\title{
Proteomic profiling of the dystrophin complex and membrane fraction from dystrophic $m d x$ muscle reveals decreases in the cytolinker desmoglein and increases in the extracellular matrix stabilizers biglycan and fibronectin
}

\author{
Sandra Murphy ${ }^{1} \cdot$ Heinrich Brinkmeier ${ }^{2} \cdot$ Mirjam Krautwald $^{2} \cdot$ Michael Henry $^{3}$. \\ Paula Meleady ${ }^{3}$ Kay Ohlendieck ${ }^{1}$ (D)
}

Received: 3 May 2017 / Accepted: 5 August 2017 / Published online: 12 August 2017

(c) Springer International Publishing AG 2017

\begin{abstract}
The almost complete loss of the membrane cytoskeletal protein dystrophin and concomitant drastic reduction in dystrophin-associated glycoproteins are the underlying mechanisms of the highly progressive neuromuscular disorder Duchenne muscular dystrophy. In order to identify new potential binding partners of dystrophin or proteins in close proximity to the sarcolemmal dystrophin complex, proteomic profiling of the isolated dystrophin-glycoprotein complex was carried out. Subcellular membrane fractionation and detergent solubilisation, in combination with ion exchange, lectin chromatography and density gradient ultracentrifugation, was performed to isolate a dystrophin complex-enriched fraction. Following gradient gel electrophoresis and on-membrane digestion, the protein constituents of the dystrophin fraction were determined by peptide mass spectrometry. This proteomic strategy resulted in the novel identification of desmoglein and desmoplakin, which act as cytolinker proteins and possibly exist in close proximity to the dystrophin complex in the sarcolemma membrane. Interestingly, comparative immunoblotting showed a significant reduction in desmoglein in dystrophin-deficient $m d x$ skeletal muscles, reminiscent of the pathobiochemical
\end{abstract}

Electronic supplementary material The online version of this article (doi:10.1007/s10974-017-9478-4) contains supplementary material, which is available to authorized users.

Kay Ohlendieck

kay.ohlendieck@mu.ie

1 Department of Biology, Maynooth University, National University of Ireland, Maynooth, County Kildare, Ireland

2 Institute of Pathophysiology, University Medicine Greifswald, 17495 Karlsburg, Germany

3 National Institute for Cellular Biotechnology, Dublin City University, Dublin 9, Ireland fate of the dystrophin-associated core proteins in muscular dystrophy. Comparative membrane proteomics was used to correlate this novel finding to large-scale changes in the dystrophic phenotype. A drastic increase in the extracellular stabilizers biglycan and fibronectin was shown by both mass spectrometric analysis and immunoblotting. The reduced expression of desmoglein in dystrophin-deficient skeletal muscles, and simultaneous increase in components of the extracellular matrix, suggest that muscular dystrophy is associated with plasmalemmal disintegration, loss of cellular linkage and reactive myofibrosis.

Keywords Biglycan - Desmoglein · Desmoplakin · Dystrophin · Dystrophinopathy $\cdot$ Fibronectin

\section{Introduction}

The largest gene in the human genome, the $2.4 \mathrm{Mb} D m d$ gene, contains seven promoters and encodes a variety of isoforms of the protein dystrophin ranging in molecular mass from 71 to $427 \mathrm{kDa}$ (Muntoni et al. 2003). The full-length isoform of dystrophin, Dp427, is a membrane cytoskeletal protein that exists in a membrane-associated supramolecular complex (Murphy and Ohlendieck 2015). The dystrophin complex mediates membrane stabilization during excitation-contraction-relaxation cycles and functions as a scaffold for various signalling proteins (Le Rumeur et al. 2010; Constantin 2014). In Duchenne muscular dystrophy, primary abnormalities in the Dmd gene are the underlying cause for the almost complete absence of Dp427 in skeletal muscles and the heart, as well as changes in the dystrophin isoform expression pattern in the central nervous system (Guiraud et al. 2015). Dystrophin-deficient skeletal muscles are characterized by a drastic reduction in dystrophin-associated 
proteins, such as dystroglycans, sarcoglycans, sarcospan, dystrobrevin and syntrophins (Ohlendieck 1996). This results in down-stream abnormalities in cellular signalling, membrane integrity and energy metabolism (Allen et al. 2016).

In order to better understand the pathobiochemical complexity of dystrophinopathy and the potential interconnectivity of damage pathways, mass spectrometry-based proteomics has been widely applied to study dystrophic skeletal muscles, cardiac abnormalities, the impaired central nervous system and serum changes, as outlined in recent reviews (Fuller et al. 2016; Hathout et al. 2016). The deficiency in dystrophin was shown to be associated with changes in ion homeostasis, excitation-contraction coupling, cellular signalling, the stress response and energy metabolism (Guevel et al. 2011; Rayavarapu et al. 2013; Roberts et al. 2015; Fröhlich et al. 2016; Lardenois et al. 2016). In addition, stabilizing structures of the cytoskeleton and the extracellular matrix are drastically altered (Holland et al. 2013). In contrast, only a limited number of studies have focused on the proteomics of the core dystrophin complex (Murphy and Ohlendieck 2015). The proteomic characterization of the dystrophin-glycoprotein complex has employed mass spectrometric surveys of separated protein assemblies using one-dimensional gel electrophoresis (Lewis and Ohlendieck 2010), immuno-precipitation (Yoon et al. 2012) and gradient centrifugation (Turk et al. 2016).

Building on these proteomic surveys and previous biochemical purification studies of dystrophin (Ervasti et al. 1990, 1991), we used here a combination of differential centrifugation, detergent solubilisation, ion exchange chromatography, lectin affinity chromatography, density gradient ultracentrifugation, gradient one-dimensional gel electrophoresis, on-membrane protein digestion and peptide mass spectrometry to characterize the dystrophin complexenriched fraction from skeletal muscle by proteomic means. The mass spectrometric analysis of normal skeletal muscle resulted in the identification of the cytolinker protein desmoglein (Kljuic and Christiano 2003), in conjunction with desmoplakin (Boyer et al. 2010), as an interesting new candidate protein that possibly exists in close relationship to the core sarcolemmal dystrophin-glycoprotein complex. Interestingly, comparative immunoblotting revealed a drastic decrease of the desmoglein isoform DSG1 in dystrophindeficient muscles, which resonates the molecular fate of other dystrophin-associated proteins (Ervasti et al. 1990; Ohlendieck et al. 1993; Murphy and Ohlendieck 2015).

To relate this novel finding to proteome-wide alterations in the dystrophic phenotype, a comparative mass spectrometric analysis of the membrane-enriched fraction from dystrophic $m d x$ quadriceps muscle was carried out. The reduction in desmoglein and deficiency in dystrophin was shown to be related to increased levels of the extracellular matrix linker proteins biglycan (Amenta et al. 2011) and fibronectin, indicating that sarcolemmal disintegration is associated with distinct changes in the matrisome (Bowe et al. 2000; Holland et al. 2016). Hence, the proteomic and biochemical profiling of normal versus dystrophic muscles presented in this report indicates new pathophysiological roles of desmoglein, biglycan and fibronectin in X-linked muscular dystrophy.

\section{Experimental section}

\section{Materials}

For the gel- and liquid chromatography-based proteomic and biochemical profiling of the dystrophin complex and membrane fractions from skeletal muscles, analytical grade reagents and materials were purchased from GE Healthcare (Little Chalfont, Buckinghamshire, UK), Sigma Chemical Company (Dorset, UK), Bio-Rad Laboratories (HemelHempstead, Hertfordshire, UK) and National Diagnostics (Atlanta, GA, USA). Proteolytic digestion was carried out with sequencing grade modified trypsin and Lys-C enzymes from Promega (Madison, WI, USA). Materials for immunoblotting included Whatman nitrocellulose transfer membranes from Invitrogen (Carlsbad, CA, USA), chemiluminescence substrate from Roche Diagnostics (Mannheim, Germany) and the reversible membrane stain MemCode from Thermo Fisher Scientific (Waltham, MA, USA). Primary antibodies were purchased from Abcam, Cambridge, UK (ab124798 to desmoglein isoform DSG1, ab2413 to fibronectin, ab58562 to biglycan, ab52488 to lactate dehydrogenase, ab14739 to the voltage-dependent anion-selective channel protein VDAC-1, and ab16048 to lamin-B1), and Sigma-Aldrich, Dorset, UK (L9393 to laminin). Peroxidase-conjugated secondary antibodies were obtained from Chemicon International (Temecula, CA, USA).

\section{Skeletal muscle preparations}

The initial proteomic screening for new potential binding partners of dystrophin was carried out with a membrane fraction isolated from combined hind limb and back muscle tissues of normal adult New Zealand white rabbits, which were kept under standard conditions according to Irish legislation on the use of animals in experimental research (Lewis and Ohlendieck 2010). Muscle samples from eight rabbits were obtained as freshly dissected post-mortem specimens from the Bioresource Facility of the National University of Ireland and transported as quick-frozen tissue specimens to Maynooth University on dry ice in accordance with the Department of Agriculture animal by-product register number 2016/16 (Department of Biology, Maynooth University). 
For the comparative proteomic profiling of the membraneenriched fraction from dystrophic mice, quadriceps femoris muscle specimens from the 100-day-old $m d x$ mouse model of Duchenne muscular dystrophy (C57BL/10 ScSnDmdmdx/J) and age-matched wild type C57BL/10 ScSnJ controls were obtained from the Animal Facility of the University of Greifswald, Germany (Holland et al. 2015). The histological assessment of $m d x$ quadriceps femoris muscle morphology was carried out with standardized haematoxylin/eosin staining of transverse cryosections, as previously described in detail (Carberry et al. 2013; Zschüntzsch et al. 2016). The entire mouse population used for experimental optimisation, comparative proteomics and verification analysis consisted of 24 animals (12 wild type versus 12 $m d x$ mice). Twice eight muscle preparations were used for comparative proteomics whereby one set of biological repeats consisted of the pooled quadriceps femoris muscle from both legs of two mice. For comparative immunoblotting, longissimus dorsi muscle, diaphragm and cardiac muscle were also used. Mice were kept under standard conditions and all procedures were carried out in accordance with German guidelines. The use of animals for scientific experiments was approved by the District Veterinary Office in Anklam, Germany. Animals were sacrificed by cervical dislocation after short ether anaesthesia and individual muscles dissected and immediately quick-frozen in liquid nitrogen and stored at $-80^{\circ} \mathrm{C}$ prior to usage.

\section{Biochemical isolation of the dystrophin-enriched fraction from skeletal muscle}

All procedures were carried out at $4{ }^{\circ} \mathrm{C}$ and buffers were supplemented with a protease inhibitor cocktail containing $0.2 \mathrm{mM}$ pefabloc, $0.3 \mu \mathrm{M}$ E-64, $1.4 \mu \mathrm{M}$ pepstatin-A, $1 \mu \mathrm{M}$ leupeptin, $0.5 \mu \mathrm{M}$ soybean trypsin inhibitor, $0.15 \mu \mathrm{M}$ aprotinin and $1 \mathrm{mM}$ EDTA. Crude microsomes were prepared from rabbit muscle homogenates by differential centrifugation as previously described in detail (Ohlendieck et al. 1991). Membrane-associated proteins were solubilized with the detergent digitonin and then fractionated by ion exchange chromatography and wheat germ agglutinin chromatography (Campbell and Kahl 1989). Ultracentrifugation with a sucrose density gradient was used to isolate a dystrophinenriched fraction that contains the core members of the dystrophin-associated glycoprotein complex (Ervasti et al. 1990).

\section{Gradient gel electrophoresis of dystrophin complex and on-membrane digestion}

A Protean IIxi Cell system from BioRad Laboratories (Hemel-Hempstead, Hertfordshire, UK) with $16 \mathrm{~cm}$-long and $1.5 \mathrm{~mm}$-thick one-dimensional $3-12 \%$ gradient gels and $100 \mu \mathrm{g}$ of total protein per lane was used to carry out sodium dodecyl sulfate polyacrylamide gel electrophoresis at a constant setting of $200 \mathrm{~V}$ (Staunton and Ohlendieck 2012). The electrophoretically separated dystrophin fraction was then transferred to nitrocellulose for $90 \mathrm{~min}$ at $100 \mathrm{~V}$ with the help of a large Transblot Cell from BioRad Laboratories. The reversible protein dyes MemCode or Ponceau-S Red were employed to visualize transfer efficiency. Coomassie staining of polyacrylamide gels showed only very few remaining faint protein bands following successful transfer. For on-membrane digestion, nitrocellulose strips with the enriched dystrophin fraction were placed in $15 \mathrm{ml}$ Falcon tubes and completely de-stained with $0.9 \%(\mathrm{w} / \mathrm{v}) \mathrm{NaCl}$ and $50 \mathrm{mM}$ sodium phosphate, $\mathrm{pH}$ 7.4. Following repeated washing with distilled water, strips were blocked with $0.5 \%$ polyvinylpyrrolidone for $40 \mathrm{~min}$ at $37^{\circ} \mathrm{C}$ with gentle agitation and washed again with distilled water before placement in new $15 \mathrm{ml}$ Falcon tubes (Luque-Garcia and Neubert 2009). Reconstituted sequencing grade trypsin was freshly added to digestion buffer consisting of $100 \mathrm{mM}$ ammonium bicarbonate/10\% acetonitrile (ACN) $(1: 1, v / v)$. Nitrocelluose sheets were incubated overnight at $37^{\circ} \mathrm{C}$ with agitation in this digestion buffer at a 1:20 ratio of trypsin to protein. Next morning, extraction buffer [ $5 \%$ formic acid/acetonitrile $(1: 2, \mathrm{v} / \mathrm{v})]$ was added and nitrocellulose strips incubated for 15 min at $37{ }^{\circ} \mathrm{C}$ with agitation (Shevchenko et al. 2006). The peptide-containing supernatant was transferred to $1.5 \mathrm{ml}$ micro-centrifuge tubes and vacuum centrifugation was used to generate a dried peptide fraction, which was re-suspended in $0.5 \%$ trifluoroacetic acid (TFA)/5\% ACN $(1: 1, \mathrm{v} / \mathrm{v})$. Centrifugation through $22-\mu \mathrm{m}$ acetate cellulose spin filter tubes for $20 \mathrm{~min}$ was employed to remove any membrane particles and $\mathrm{C} 18$ spin columns used to desalt peptides prior to drying by vacuum centrifugation and mass spectrometric analysis.

\section{Preparation of membrane-enriched fraction from wild type versus dystrophic $m d x$ quadriceps femoris muscle}

For the comparative proteomic profiling of the quadriceps femoris muscle from wild type versus dystrophic $m d x$ mice, a crude membrane-enriched fraction containing mitochondria, sarcoplasmic reticulum and surface membranes, as well as associated components of the extracellular matrix and membrane cytoskeleton, was isolated by an optimized differential centrifugation method (O'Connell and Ohlendieck 2009). Briefly, muscle specimens (1 mg wet weight) were finely chopped and homogenised in $10 \mathrm{ml}$ of $2 \mathrm{mM}$ HEPES, $\mathrm{pH}$ 7.4, $220 \mathrm{mM}$ mannitol, $70 \mathrm{mM}$ sucrose (supplemented with a protease inhibitor cocktail) and the homogenate centrifuged at $1100 \mathrm{~g}$ for $5 \mathrm{~min}$ to remove cell debris and nuclei. The membrane-containing supernatant was retained while the pellet was re-suspended in $5 \mathrm{ml}$ of buffer and re-centrifuged. This step was repeated once more with the pellet 
re-suspended in $2.5 \mathrm{ml}$ of buffer. The supernatants from each of these centrifugation steps were pooled and centrifuged at $7000 \mathrm{~g}$ for $15 \mathrm{~min}$ and the resulting pellet was re-suspended in $5 \mathrm{ml}$ of buffer and then centrifuged at 20,000 $\mathrm{g}$ for $15 \mathrm{~min}$ to sediment the crude membrane fraction. This step was repeated two more times, with the pellet retained at each stage. After the final centrifugation step, the pellets were pooled together and re-suspended in $2 \mathrm{ml}$ of buffer.

\section{Generation of peptide populations from membrane-enriched fraction}

For the generation of distinct peptide populations, membrane fractions from normal versus dystrophic muscles were pre-treated with the Ready Prep 2D clean-up kit from BioRad Laboratories (Hemel-Hempstead, Hertfordshire, UK), and the pellets obtained were re-suspended in label-free solubilisation buffer consisting of $6 \mathrm{M}$ urea, $2 \mathrm{M}$ thiourea and $10 \mathrm{mM}$ Tris, $\mathrm{pH} 8.0$ in LC-MS grade water (Holland et al. 2015). Sample volumes were equalised with labelfree solubilisation buffer, reduced with $10 \mathrm{mM}$ DTT for $30 \mathrm{~min}$ at $37{ }^{\circ} \mathrm{C}$ and alkylated with $25 \mathrm{mM}$ iodoacetamide in $50 \mathrm{mM}$ ammonium bicarbonate for $20 \mathrm{~min}$ in the dark at room temperature. Samples were then treated with a further $10 \mathrm{mM}$ DTT for $15 \mathrm{~min}$ in the dark at room temperature to quench any remaining unreacted iodoacetamide (Murphy et al. 2015). Sequential proteolytic digestion was conducted with an initial step using Lys-C enzyme at a ratio of 1:100 (protease:protein) for $4 \mathrm{~h}$ at $37{ }^{\circ} \mathrm{C}$, followed by dilution of samples with four times the initial sample volume in $50 \mathrm{mM}$ ammonium bicarbonate to reduce the urea concentration prior to tryptic digestion, and a second step with sequencinggrade trypsin at a ratio of 1:25 (protease:protein) overnight at $37{ }^{\circ} \mathrm{C}$ (Dowling et al. 2014). Digestion was halted using $2 \%$ TFA in $20 \%$ ACN (3:1 (v/v) dilution). Peptide suspensions were purified with Pierce C18 Spin Columns from Thermo Fisher Scientific (Dublin, Ireland), dried through vacuum centrifugation and re-suspended in loading buffer consisting of $2 \% \mathrm{ACN}$ and $0.05 \%$ TFA in LC-MS grade water.

\section{Label-free liquid chromatography mass spectrometry}

An Ultimate 3000 NanoLC system (Dionex Corporation, Sunnyvale, CA, USA) coupled to a Q-Exactive mass spectrometer (Thermo Fisher Scientific) was used in this study for the label-free liquid chromatography mass spectrometric (LC-MS/MS) analysis of the dystrophin-enriched fraction from rabbit skeletal muscle and the crude membrane fraction from wild type versus $m d x$ quadriceps femoris mouse muscle. Peptide mixtures $(5 \mu \mathrm{l}$, corresponding to $1 \mu \mathrm{g}$ pre-digested protein) were loaded by an autosampler onto a C18 trap column (C18 PepMap, $300 \mu \mathrm{m}$ id $\times 5 \mathrm{~mm}$,
$5 \mu \mathrm{m}$ particle size, $100 \AA$ A pore size; Thermo Fisher Scientific). The trap column was switched on-line with an analytical Biobasic C18 Picofrit column (C18 PepMap, $75 \mu \mathrm{m}$ id $\times 50 \mathrm{~cm}, 2 \mu \mathrm{m}$ particle size, $100 \AA$ pore size; Dionex).

Peptides obtained from the crude membrane fraction from wild type versus $m d x$ quadriceps femoris mouse muscle were eluted using the following binary gradients: solvent A [2\% (v/v) ACN and $0.1 \%(\mathrm{v} / \mathrm{v})$ formic acid in LC-MS grade water] and solvent B $[80 \%(\mathrm{v} / \mathrm{v}) \mathrm{ACN}$ and $0.1 \%(\mathrm{v} / \mathrm{v})$ formic acid in LC-MS grade water]. Peptides were eluted as follows: $5 \%$ solvent B for $120 \mathrm{~min}, 45 \%$ solvent B for $2.5 \mathrm{~min}$, $90 \%$ solvent B for 9 min and 3\% solvent B for $43 \mathrm{~min}$. The column flow rate was fixed at $0.3 \mu \mathrm{l} / \mathrm{min}$.

Peptide populations from the dystrophin-enriched fraction from rabbit skeletal muscle were eluted over a 65 -min gradient as follows; $3 \%$ solvent B for 5 min, $10 \%$ solvent B for $30 \mathrm{~min}, 40 \%$ solvent B for $5 \mathrm{~min}, 90 \%$ solvent B for $5 \mathrm{~min}$ and 3\% solvent B for $10 \mathrm{~min}$. The column flow rate was set to $0.3 \mu \mathrm{l} / \mathrm{min}$. Data were acquired with Xcalibur software (Thermo Fisher Scientific).

The Q-Exactive mass spectrometer was operated in positive, data-dependent mode and was externally calibrated. Survey MS scans were conducted in the $300-1700 \mathrm{~m} / \mathrm{z}$ range with a resolution of $140,000(\mathrm{~m} / \mathrm{z} 200)$ and lock mass set to 445.12003 (Murphy et al. 2015). Collision-induced dissociation (CID) fragmentation was carried out with the fifteen most intense ions per scan and at 17,500 resolution. A dynamic exclusion window was applied within $30 \mathrm{~s}$. An isolation window of $2 \mathrm{~m} / \mathrm{z}$ and one microscan were used to collect suitable tandem mass spectra. Pre-run and post-run control HeLa cells were run and the acquired mass spectra were analysed by Proteome Discoverer to verify the reproducibility of the LC-MS/MS system.

\section{Proteomic profiling by label-free liquid chromatography mass spectrometry}

Qualitative analysis of the dystrophin-enriched fraction from rabbit skeletal muscle was performed using Proteome Discoverer 1.4 against Sequest HT (SEQUEST HT algorithm, licence Thermo Scientific, registered trademark University of Washington, USA) using the UniProtKB database with 24,202 proteins. Since the rabbit genome is incomplete, mass spectrometry raw files were searched against both the Oryctolagus cuniculus database and the Mammalia database (Liu et al. 2016). For proper protein identification, the following search parameters were used: (1) peptide mass tolerance set to $10 \mathrm{ppm}$, (2) MS/MS mass tolerance set to $0.02 \mathrm{Da}$, (3) up to two missed cleavages, (4) carbamidomethylation set as a fixed modification and (5) methionine oxidation set as a variable modification. Peptides were subsequently filtered 
using a minimum XCorr score of 1.5 for $1,2.0$ for 2, 2.25 for 3 and 2.5 for 4 charge states, with peptide probability set to high confidence.

Progenesis QI for Proteomics software (version 3.1; Non-Linear Dynamics, a Waters company, Newcastle upon Tyne, UK) was used for quantitative analysis of the raw data obtained from LC-MS/MS of the crude membrane fraction from wild type versus $m d x$ quadriceps femoris mouse muscle. The run containing the most peptide ions was manually selected as the reference run and all other runs were aligned to this, thus allowing for any drift in retention time and giving an adjusted retention time for all runs in the analysis (Di Luca et al. 2015). A number of filters were applied to the MS/MS data files prior to being exported as a MASCOT generic file (mgf) to Proteome Discoverer 2.1 (Thermo Scientific): (1) peptide features with ANOVA $\leq 0.05$ between experimental groups, (2) mass peaks with charge states from +1 to +6 and (3) greater than one isotope per peptide (Holland et al. 2015). Protein identification was performed using Proteome Discoverer 2.1 against Mascot (version 2.3, Matrix Science, Boston, MA, USA) and Sequest HT (SEQUEST HT algorithm, licence Thermo Scientific, registered trademark University of Washington, USA) using the UniProtKB-SwissProt database with 24,752 proteins. For the comparative proteomic analysis of the $m d x$ mouse model, searches were carried out with the Mus musculus database. The search parameters used were: (1) peptide mass tolerance set to $10 \mathrm{ppm}$, (2) MS/MS mass tolerance set to $0.02 \mathrm{Da}$, (3) a maximum of two missed cleavages allowed, (4) carbamidomethylation set as a fixed modification and (5) methionine oxidation set as a variable modification (Murphy et al. 2015). For re-importation back into Progenesis LC-MS software as a PepXML file only peptides with either ion scores of 40.00 or more (from Mascot) and peptides with XCorr score $>1.5$ (from Sequest HT) were allowed. The following criteria were applied to assign proteins as confidently identified: (1) an ANOVA score between experimental groups of $\leq 0.05$, and (2) proteins with $\geq 2$ peptides matched.

Standard bioinformatics software was used to catalogue the clustering of differentially abundant proteins in the membrane-enriched fraction from dystrophic $m d x$ muscle using the PANTHER database of protein families (http:// pantherdb.org; version 10.0) for the classification of protein class (Mi et al. 2013).

\section{Comparative immunoblot analysis}

Immunoblotting was employed for both the confirmation of membrane enrichment and for the verification of some of the key protein hits identified by mass spectrometric analysis. Total tissue extracts were prepared from quadriceps femoris, longissimus dorsi, diaphragm and cardiac muscle from wild type versus $m d x$ mice by a previously optimized method (Murphy et al. 2015). Standardized one-dimensional gel electrophoresis was performed with $10 \%$ polyacrylamide gels, followed by wet transfer at $100 \mathrm{~V}$ for $70 \mathrm{~min}$ at $4{ }^{\circ} \mathrm{C}$ to Whatman nitrocellulose membranes in a Trans-Blot Cell from Bio-Rad Laboratories, as previously described (Murphy et al. 2016). For comparative analyses, silver staining of protein gels and routine immunoblotting was carried out with 10 and $25 \mu \mathrm{g}$ of total protein per lane, respectively. Membranes were blocked for $1 \mathrm{~h}$ at room temperature using a milk protein solution $[2.5 \%(\mathrm{w} / \mathrm{v})$ fat-free milk powder in $10 \%$ phosphate buffered saline], and then incubated with appropriately diluted primary antibodies overnight at $4{ }^{\circ} \mathrm{C}$ with gentle agitation. The following day, membranes were washed twice in the milk protein solution for $10 \mathrm{~min}$ and then incubated with peroxidase-conjugated secondary antibodies for $1.5 \mathrm{~h}$ at room temperature with gentle agitation. Membranes were washed with the milk protein solution and then with $10 \%$ phosphate-buffered saline (Murphy et al. 2016). The enhanced chemiluminescence method was used to visualise immuno-decorated protein bands (O'Connell and Ohlendieck 2009). Densitometric scanning and statistical analysis of immunoblots was performed using a HP PSC2355 scanner and ImageJ software (NIH, Bethesda, MD, USA) along with Graph-Pad Prism software (San Diego, CA, USA), in which a $p$ value $<0.05$ was deemed to be statistically significant.

\section{Results}

\section{Mass spectrometric identification of core members of the dystrophin-associated complex from skeletal muscle}

The dystrophin complex-enriched fraction from rabbit skeletal muscle, isolated by an established combination of sequential liquid chromatography and sucrose gradient ultracentrifugation (Ervasti et al. 1990), was clearly shown to contain the Dp427 isoform of the membrane cytoskeletal protein dystrophin. The bioanalytical approach to enrich the dystrophin complex is outlined in Fig. 1A. The Ponceau S-stained nitrocellulose replica of the gel electrophoretically separated fraction enriched in the rabbit muscle dystrophin-glycoprotein complex is shown in supplementary Figure S1. The mass spectrometric identification of dystrophin Dp427-M with a high Xcorr score of 119.94 was based on the information from 28 peptides with an $8.9 \%$ sequence coverage of the $426 \mathrm{kDa}$ isoform (Fig. 1b). On-membrane digestion of the dystrophin-enriched fraction and mass spectrometry revealed the presence of the core dystrophin-associated proteins named $\alpha / \beta$-dystroglycan, $\alpha$-sarcoglycan, $\beta$-sarcoglycan, 
A

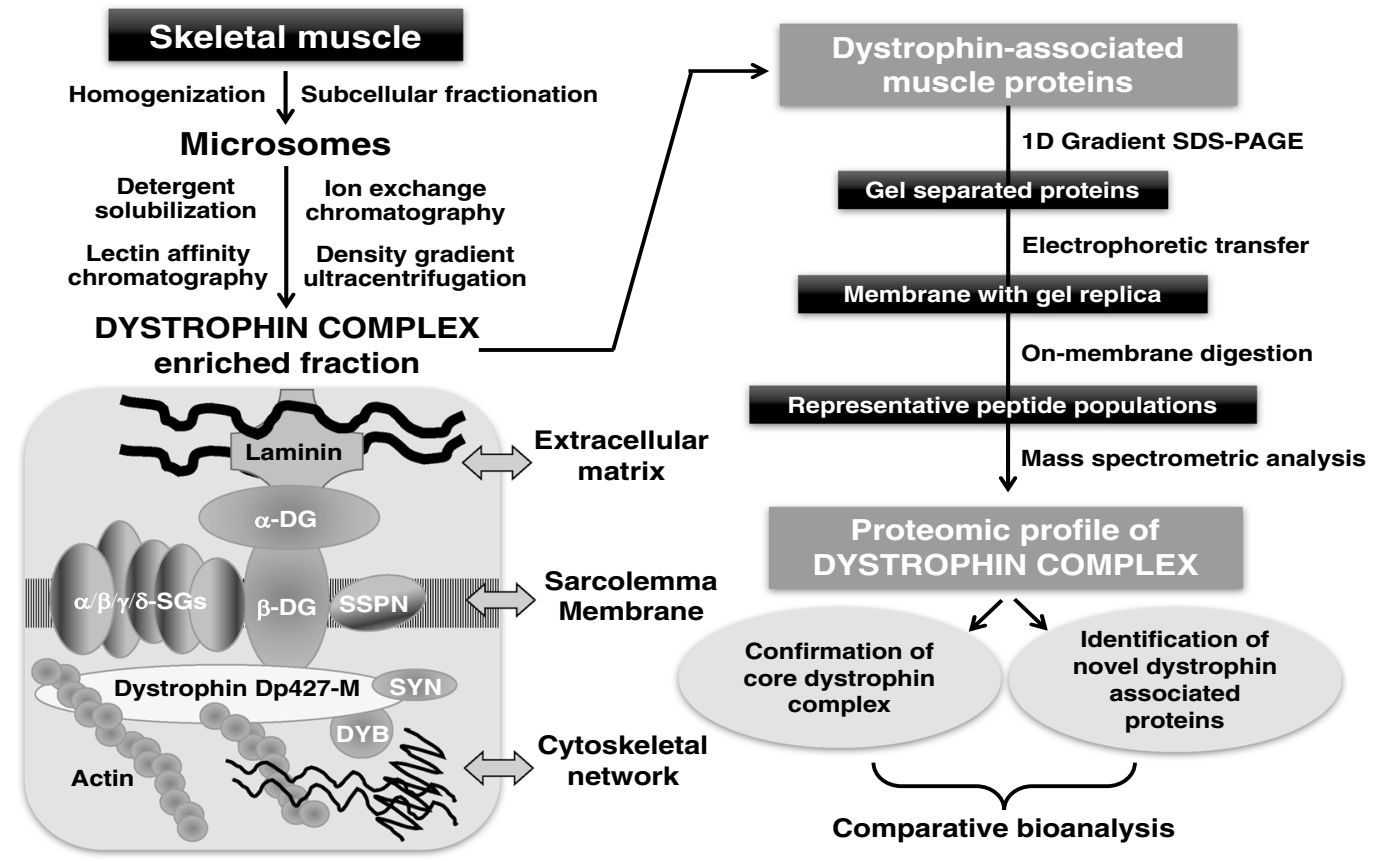

B Mass spectrometric identification of dystrophin Dp427-M

\begin{tabular}{|ccccccc|}
\hline $\begin{array}{c}\text { Gene } \\
\text { name }\end{array}$ & $\begin{array}{c}\text { Protein } \\
\text { name }\end{array}$ & $\begin{array}{c}\text { No. of } \\
\text { peptides }\end{array}$ & $\begin{array}{c}\text { Coverage } \\
\%\end{array}$ & $\begin{array}{c}\text { Xcorr } \\
\text { Score }\end{array}$ & $\begin{array}{c}\text { Molecular } \\
\text { mass (kDa) }\end{array}$ & $\begin{array}{c}\text { Calculated } \\
\text { pl }\end{array}$ \\
\hline Dmd & $\begin{array}{c}\text { Dystrophin } \\
\text { Dp427-M }\end{array}$ & 28 & 8.9 & 119.94 & 426.1 & 5.96 \\
\hline
\end{tabular}

Fig. 1 Proteomic profiling of the dystrophin complex-enriched fraction from rabbit skeletal muscle. Shown is the bioanalytical workflow used to identify dystrophin-associated proteins (a) and the mass spec- trometric identification of the full-length dystrophin isoform Dp427M (b). $D G$ dystroglycan, $D Y B$ dystrobrevin, $S G$ sarcoglycan, SSPN sarcospan, $S Y N$ syntrophin

established dystrophin-associated proteins is listed in Table 1 and demonstrated a successful enrichment of the dystrophin complex by density gradient centrifugation.

Table 1 Mass spectrometric identification of established members of the dystrophin-associated protein complex from rabbit skeletal muscle

\begin{tabular}{|c|c|c|c|c|c|c|c|}
\hline Gene name & Protein name & $\begin{array}{l}\text { No. unique } \\
\text { peptides }\end{array}$ & Coverage $(\%)$ & $\begin{array}{l}\text { Xcorr score } \\
\text { Replicate } 1\end{array}$ & $\begin{array}{l}\text { Xcorr score } \\
\text { Replicate } 2\end{array}$ & $\begin{array}{l}\text { Molecular } \\
\text { mass }(\mathrm{kDa})\end{array}$ & Calculated $\mathrm{p} I$ \\
\hline DAG1 & $\alpha / \beta$-Dystroglycan & 2 & 3.58 & 6.60 & 2.75 & 97.0 & 8.27 \\
\hline SGCA & $\alpha$-Sarcoglycan & 4 & 11.11 & 9.11 & 2.91 & 42.5 & 6.19 \\
\hline SGCB & $\beta$-Sarcoglycan & 3 & 10.06 & 8.93 & 3.64 & 34.7 & 8.76 \\
\hline SGCG & $\gamma$-Sarcoglycan & 3 & 12.37 & 10.20 & 3.68 & 32.0 & 5.25 \\
\hline SGCD & $\delta$-Sarcoglycan & 4 & 15.57 & 14.37 & 15.50 & 32.1 & 8.85 \\
\hline SNTA1 & $\alpha 1$-Syntrophin & 2 & 6.97 & 5.90 & 4.45 & 51.8 & 6.64 \\
\hline SNTB1 & $\beta 1$-Syntrophin & 4 & 11.30 & 8.60 & 8.66 & 58.3 & 8.31 \\
\hline SNTB2 & $\beta 2$-Syntrophin & 2 & 4.45 & 3.01 & 5.37 & 58.4 & 8.09 \\
\hline DTNA & $\alpha$-Dystrobrevin & 3 & 8.01 & 8.92 & - & 63.3 & 8.15 \\
\hline
\end{tabular}


Proteomic identification of co-purifying and potentially novel dystrophin-associated proteins

Besides the above listed established proteins that were previously shown to exist in close proximity to dystrophin isoform Dp427-M (Murphy and Ohlendieck 2015), interesting new candidate proteins that were identified by mass spectrometric analysis to co-purify with the dystrophin complex are presented in Table 2. These muscle proteins may exist in a close relationship to the sarcolemmal dystrophin-glycoprotein complex or are alternatively present in the dystrophin-enriched fraction as highly abundant contaminants from other cellular organelles or subcellular compartments. The identified proteins belong to diverse subcellular structures within skeletal muscles and were identified as the fast SERCA1 isoform of the $\mathrm{Ca}^{2+}$-ATPase (ATP2A1), the anion exchange protein (SLC4A1), the cytolinker desmoglein-1 (DSG1), cytokeratin-3 (KRT3), serum albumin (ALB), the cytolinker desmoplakin (DSP) and myosin heavy chain isoform IIb (MYH4). Although all of these muscle proteins may link directly or at least indirectly to members of the sarcolemmal dystrophin complex, the most likely functional interaction partners of the dystrophin complex would be presented by the cytoskeletal linker protein desmoglein (Kljuic and Christiano 2003) and its binding partner desmoplakin (Boyer et al. 2010), as well as the anion exchanger and cytokeratin, which can also interact with the cytoskeletal network (Ursitti et al. 2004; Stone et al. 2005). In contrast, the $\mathrm{Ca}^{2+}$-ATPase of the highly abundant sarcoplasmic reticulum, the myosin heavy chain of the plentiful contractile apparatus, and the frequently cross-contaminating albumin as the most abundant component of serum are less likely to present major novel dystrophin-associated components.

\section{Immunoblot analysis of the cytolinker desmoglein in dystrophic $m d x$ muscles}

Following the mass spectrometric identification of desmoglein and desmoplakin as co-purifying proteins in the dystrophin-enriched fraction from skeletal muscle, comparative immunoblotting was used to attempt the determination of the status of these cytolinkers in normal versus dystrophic specimens. However, since immuno-decoration of desmoplakin (using two commercially available antibodies) did not result in proper labelling of this protein (not shown), the subsequent immunoblotting survey focused on desmoglein isoform DSG1. Figure 2 shows the comparative analysis of quadriceps femoris and longissimus dorsi muscle. While the overall protein band patterns in silver-stained gels (Fig. 2a, d) and laminin levels (Fig. 2b, e) were shown to be comparable between crude extracts from wild type versus $m d x$ mice, the concentration of desmoglein was found to be drastically decreased in dystrophin-deficient muscle (Fig. 2c, f). The statistical evaluation of immunoblotting revealed that the reduced levels of desmoglein are significant (Fig. $2 \mathrm{~g}-\mathrm{j}$ ). The co-localization of desmoglein and dystrophin in muscle cryosections using immunofluorescence microscopy did not result in sufficient immuno-labelling for a reliable cell biological assessment (not shown). The lack of proper antibody staining is probably due to the low abundance of this cytoskeletal linker protein.

\section{Isolation and proteomic characterization of a membrane-enriched fraction from quadriceps femoris muscle}

In order to correlate the reduced abundance of the newly identified cytolinker protein desmoglein to proteome-wide changes in the dystrophic phenotype, a comparative mass spectrometric analysis of quadriceps femoris preparations from normal versus dystrophic mice was initiated. The aim was to analyse a crude membrane fraction so that on the one hand, sample complexity would be reduced to also encompass the analysis of low-abundance proteins, and on the other hand, the study of proteins derived from the surface membrane system, mitochondria and the sarcoplasmic reticulum could be achieved. The subcellular fractionation protocol for the isolation of a very crude membrane fraction employed therefore a relatively slow centrifugation step. This approach is based on an established procedure

Table 2 Mass spectrometric identification of dystrophin co-purifying proteins from rabbit skeletal muscle

\begin{tabular}{|c|c|c|c|c|c|c|c|}
\hline Gene name & Protein name & $\begin{array}{l}\text { No. unique } \\
\text { peptides }\end{array}$ & Coverage $(\%)$ & $\begin{array}{l}\text { Xcorr score } \\
\text { Replicate } 1\end{array}$ & $\begin{array}{l}\text { Xcorr score } \\
\text { Replicate } 2\end{array}$ & $\begin{array}{l}\text { Molecular } \\
\text { mass (kDa) }\end{array}$ & Calculated $\mathrm{p} I$ \\
\hline ATP2A1 & Fast SERCA1 $\mathrm{Ca}^{2+}$-ATPase & 9 & 13.76 & 18.27 & 22.67 & 107.9 & 5.31 \\
\hline SLC4A1 & Anion exchange protein & 4 & 6.31 & 15.13 & 8.08 & 102.1 & 5.24 \\
\hline DSG1 & Desmoglein-1 & 4 & 5.92 & 5.69 & 8.83 & 113.7 & 5.06 \\
\hline KRT3 & Cytokeratin-3 & 4 & 3.82 & 7.33 & 9.94 & 64.3 & 7.75 \\
\hline ALB & Serum albumin & 3 & 5.27 & 8.05 & 8.72 & 69.3 & 6.18 \\
\hline DSP & Desmoplakin & 3 & 1.73 & 3.52 & 8.33 & 278.7 & 6.95 \\
\hline MYH4 & Myosin heavy chain isoform MyHC-IIb & 2 & 1.96 & 10.63 & 2.85 & 222.9 & 5.81 \\
\hline
\end{tabular}




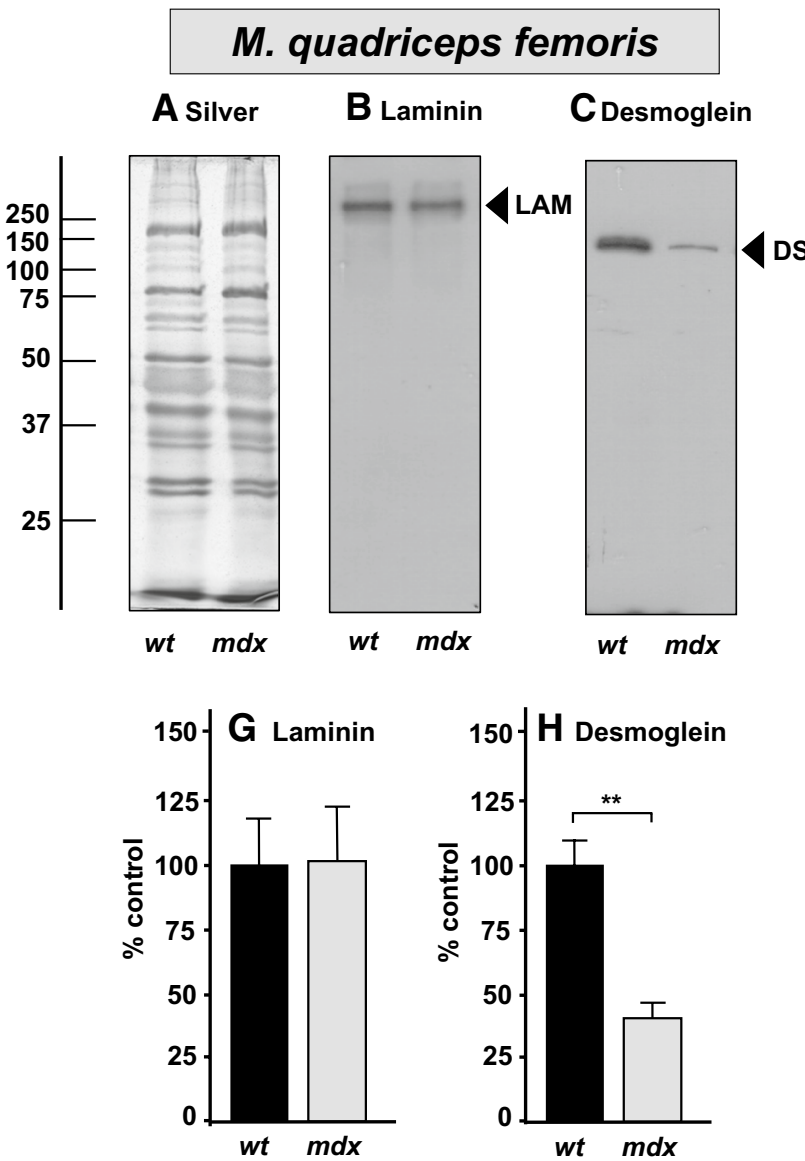

Fig. 2 Immunoblot analysis of the cytolinker protein desmoglein in dystrophin-deficient skeletal muscle extracts. Shown are silverstained gels $(A, D)$ and corresponding immunoblots labelled with antibodies to the basal lamina component laminin (LAM; $B, E$ ), and the cytolinker desmoglein isoform 1 (DSG1; $C, F$ ). Lanes 1 and 2 represent 100-day-old wild type ( $w t$ ) versus age-matched $m d x$ quadri-

especially developed for studying mitochondria (O'Connell and Ohlendieck 2009). Previous comparative proteomic investigations have employed a $100,000 \mathrm{~g}$ centrifugation step to isolate microsomes prior to mass spectrometric analysis and used combined muscles from the entire mouse hind limb of the $m d x-4 c v$ mouse (Murphy et al. 2015).

In contrast to the previous high-speed centrifugation approach to isolate the microsomal fraction, this new report focused on a select muscle group, the quadriceps femoris muscle from the $m d x$ mouse model of Duchenne muscular dystrophy, and used a lower-speed centrifugation step to study a different subset of proteins that may be affected by deficiency in dystrophin. The results of the new proteomic survey showed that the concentration of a great variety of different protein species is changed in X-linked muscular dystrophy, including many membrane-associated proteins, but also components of the extracellular matrix and the intracellular cytoskeleton.

\section{M. longissimus dorsi}

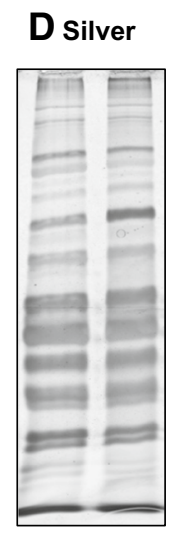

E Laminin $\quad F$ Desmoglein
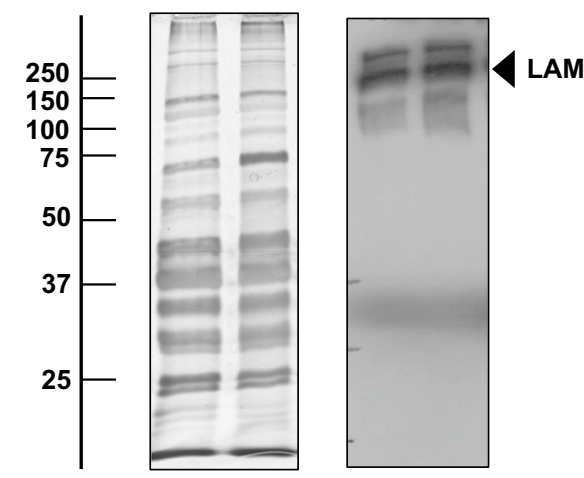

wt $m d x$
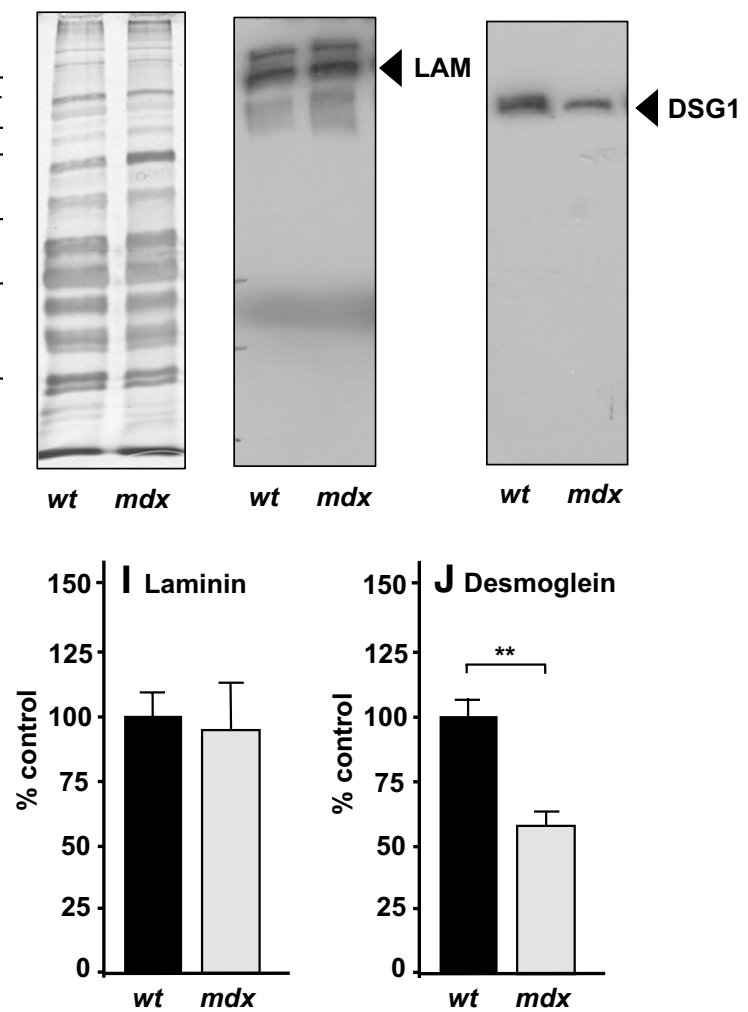

ceps femoris $(A-C)$ and longissimus dorsi $(D-F)$ muscle, respectively. Molecular mass standards are marked on the left of panels. The comparative blotting between crude extracts from wild type versus $m d x$ mice was statistically evaluated using an unpaired Student's $t$ test $($ Mean values \pm SEM; $\mathrm{n}=4 ; * * \mathrm{p}<0.01 ; G-J)$

The bioanalytical workflow is depicted in Fig. 3a. The successful subcellular fractionation and enrichment of membrane proteins was documented by reduced levels of the cytosolic marker enzyme lactate dehydrogenase and an increased concentration of the membrane protein VDAC-1 in the isolated crude membrane fraction from skeletal muscle (Fig. 3b). The total number of individual proteins in relation to specific organelles and subcellular muscle structures as determined by mass spectrometry is listed in Fig. 3c.

\section{Comparative proteomic profiling of the membrane-enriched fraction from $m d x$ quadriceps femoris muscle}

Mass spectrometry-based subproteomics revealed a large number of protein species with a changed abundance in dystrophin-deficient $m d x$ quadriceps femoris muscle. A 
Fig. 3 Isolation of membraneenriched fraction from wild type versus dystrophic skeletal muscle. Shown is the workflow of the isolation of the membrane-enriched fraction from normal and dystrophic mdx quadriceps femoris muscle and subsequent comparative proteomic profiling (a). In $\mathbf{b}$ is shown a silver-stained gel and corresponding immunoblots labelled with antibodies to the membrane marker VDAC-1 and the cytosolic marker lactate dehydrogenase. Lanes 1 to 4 represent total extracts and enriched membranes isolated from wild type (wt) and $m d x$ quadriceps femoris muscle, respectively. Molecular mass standards are marked on the left of panels. The total number of mass spectrometrically identified muscle proteins in relation to different organelles and subcellular structures is summarized in c. Protein data are based on the annotation feature in the Proteome Discoverer 2.1 software program

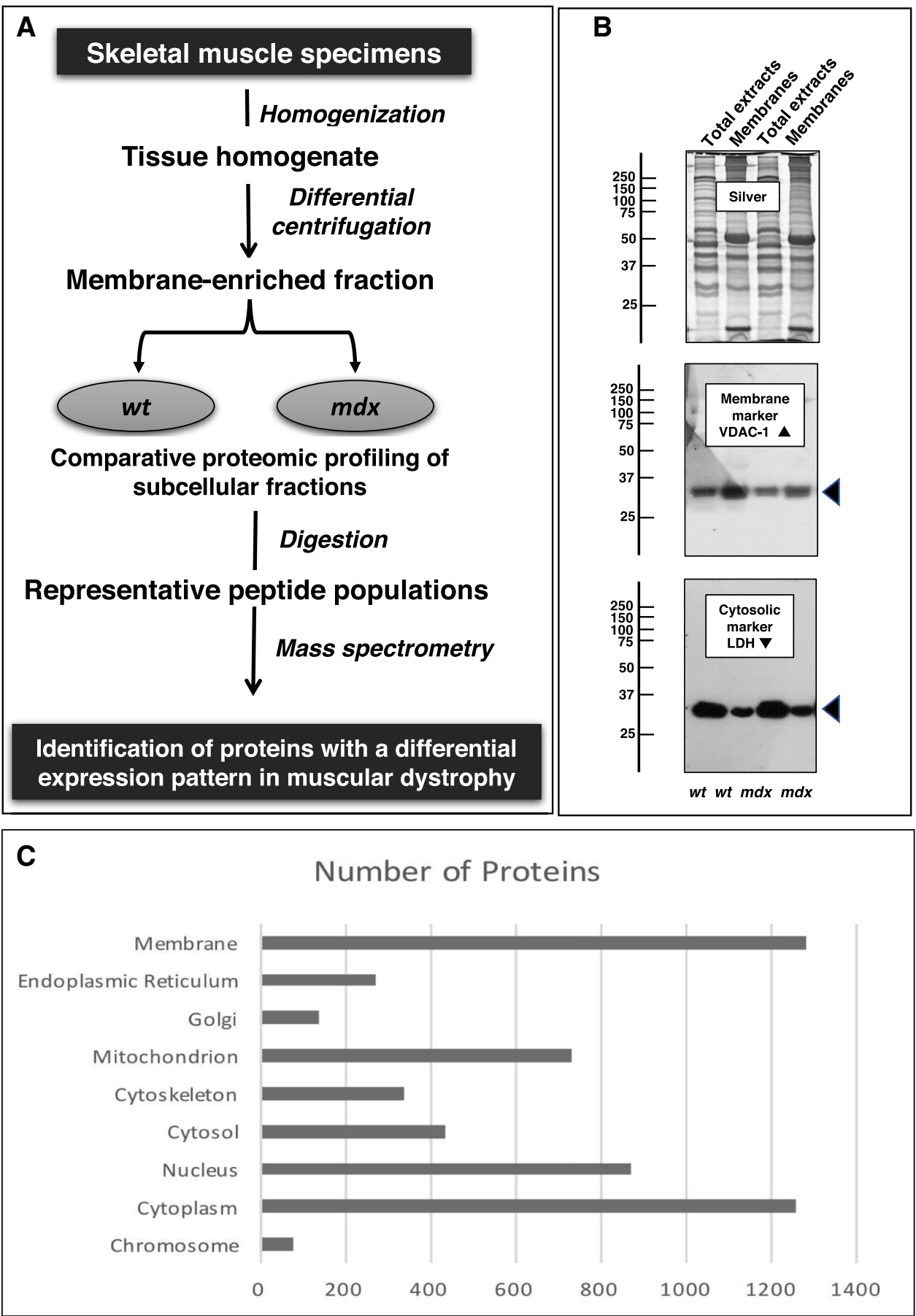

histological assessment of wild type muscle morphology versus the dystrophic phenotype is shown in Fig. 4, demonstrating a high fraction of central nucleation and a greater variability of fibre diameters in the mdx quadriceps femoris muscle. Detailed overviews of haematoxylin and eosin stained skeletal muscles from the dystrophic $m d x$ mouse model of Duchenne muscular dystrophy have previously been published (Carberry et al. 2013), including quadriceps femoris muscle (Zschüntzsch et al. 2016). Tables 3 and 4 list major muscle proteins with a significantly reduced versus increased density in dystrophic muscle, respectively. Supplementary Table S1 consists of an additional list of increased proteins with a lower fold-change as presented in Table 4. A summary of these findings is given in Fig. 5 showing graphically the bioinformatics PANTHER analysis of changed protein classes. Importantly, the most drastically reduced protein in membranes from dystrophic muscle tissue was identified as the Dp427-M isoform of dystrophin, which confirms the mutant status of the $m d x$ mouse model of Duchenne muscular dystrophy used in this investigation 
Fig. 4 Histological analysis of wild type ( $w t)$ versus dystrophic $m d x$ skeletal muscle. Shown are transverse sections of quadriceps femoris muscles from 100day old wild type (a) and $m d x$ (b) mice. Cryosections were stained with hematoxylin and eosin. Bar equals $50 \mu \mathrm{m}$
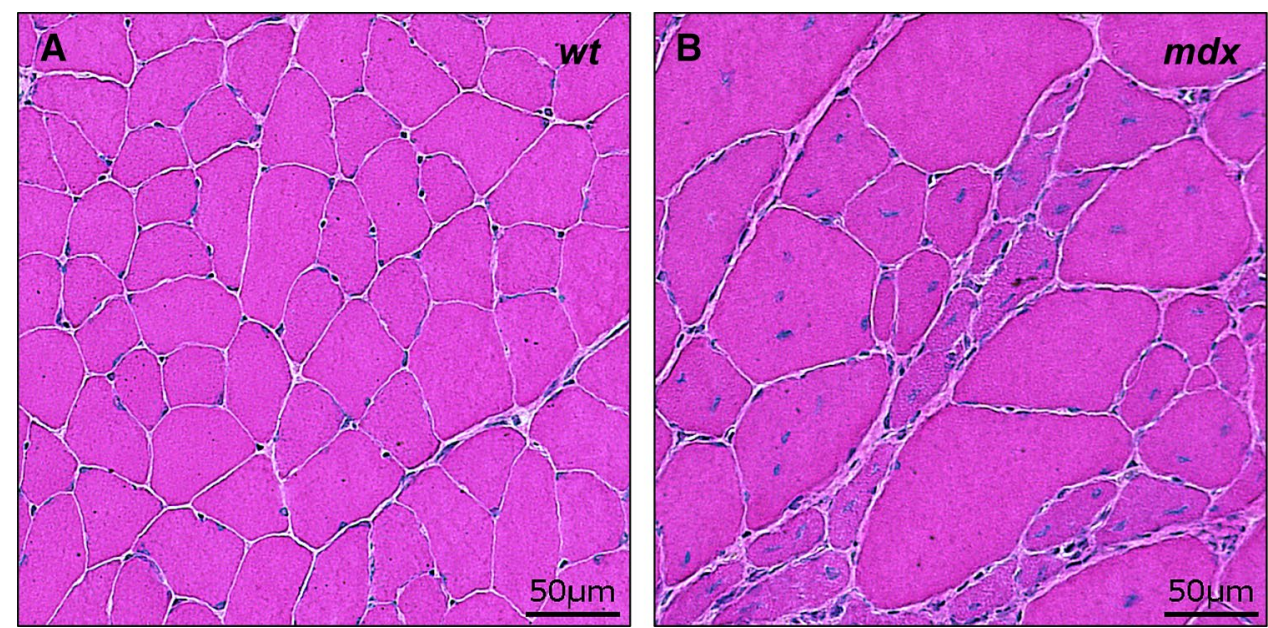

Table 3 Mass spectrometric identification of proteins with a reduced abundance in the dystrophic mdx quadriceps femoris muscle

\begin{tabular}{|c|c|c|c|c|c|c|}
\hline Accession number & Gene name & Protein name & $\begin{array}{l}\text { Unique } \\
\text { peptides }\end{array}$ & Confidence score & Anova (p) & Fold change \\
\hline P11531 & Dmd & Dystrophin Dp427-M & 3 & 167.07 & $8.23 \mathrm{E}-05$ & -56.75 \\
\hline P15949 & Klk1b9 & Kallikrein 1-related peptidase b9 & 3 & 196.89 & 0.0083 & -29.71 \\
\hline P23953 & Ces1c & Carboxylesterase 1C & 4 & 262.6 & 0.0062 & -18.92 \\
\hline P12710 & Fabp1 & Fatty acid-binding protein, liver & 2 & 116.96 & 0.0370 & -8.53 \\
\hline Q8R429 & Atp2a1 & SERCA1 Calcium-ATPase & 2 & 103.52 & 0.0240 & -6.46 \\
\hline Q00623 & Apoa1 & Apolipoprotein A-I & 4 & 179.01 & 0.0382 & -5.27 \\
\hline P21107 & Tpm3 & Tropomyosin alpha-3 chain & 5 & 304.33 & 0.0003 & -4.32 \\
\hline P09542 & Myl3 & Myosin light chain 3 & 4 & 240.66 & 0.0010 & -3.46 \\
\hline Q91Z83 & Myh7 & Myosin-7 & 17 & 1199.37 & 0.0080 & -3.43 \\
\hline Q8CI51 & Pdlim5 & PDZ and LIM domain protein 5 & 2 & 146.73 & 0.0455 & -2.34 \\
\hline Q9JJW5 & Myoz2 & Myozenin-2 & 3 & 207.04 & 0.0018 & -2.16 \\
\hline Q5XKE0 & Mybpc2 & Myosin-binding protein $\mathrm{C}$, fast-type & 3 & 166.12 & 0.0076 & -2.07 \\
\hline P10649 & Gstm1 & Glutathione S-transferase $\mathrm{Mu} 1$ & 3 & 161.17 & 0.0073 & -1.92 \\
\hline Q3V1D3 & Ampd1 & AMP deaminase 1 & 2 & 157.93 & 0.0310 & -1.85 \\
\hline P58771 & Tpm1 & Tropomyosin alpha-1 chain & 3 & 264.03 & 0.0371 & -1.79 \\
\hline Q62234 & Myom1 & Myomesin-1 & 2 & 119.56 & 0.0379 & -1.62 \\
\hline Q9WUB3 & Pygm & Glycogen phosphorylase, muscle form & 6 & 437.86 & 0.0196 & -1.48 \\
\hline Q5SX39 & Myh4 & Myosin-4 & 8 & 667.87 & 0.0484 & -1.47 \\
\hline P47934 & Crat & Carnitine O-acetyltransferase & 2 & 192.68 & 0.0217 & -1.47 \\
\hline
\end{tabular}

(Table 3). Since the significant increase in fibronectin and biglycan indicated remodelling of the extracellular matrix (Table 4), immunoblotting was used to independently verify these proteomic results.

\section{Immunoblot analysis of fibronectin and biglycan in dystrophic $m d x$ muscles}

Following the proteomic identification of desmoglein as being potentially a novel dystrophin-associated protein with a reduction in muscular dystrophy, the status of the extracellular matrix proteins fibronectin and biglycan was evaluated by immunoblotting. Comparative immunolabelling of fibronectin revealed an elevated density of this extracellular protein in crude extracts from $m d x$ quadriceps femoris (Fig. 6c) and longissimus dorsi (Fig. 6f) muscles. In contrast, general protein expression levels and laminin abundance were found to be comparable between wild type and dystrophic muscle preparations (Fig. 6a, b, d, e). The elevated concentration of fibronectin was shown to be statistically significant (Fig. $6 \mathrm{~g}-\mathrm{j}$ ).

The dystrophin complex-associated protein biglycan was also found to be elevated in $m d x$ muscle extracts. Immunoblotting had to be carried out under non-reducing 
Table 4 Mass spectrometric identification of proteins with an increased abundance in the dystrophic mdx quadriceps femoris muscle

\begin{tabular}{|c|c|c|c|c|c|c|}
\hline Accession & Gene name & Protein name & $\begin{array}{l}\text { Unique } \\
\text { peptides }\end{array}$ & Confidence score & Anova (p) & Fold change \\
\hline P13542 & Myh8 & Myosin-8 & 7 & 445.03 & $1.29 \mathrm{E}-06$ & 486.30 \\
\hline Q9WTR5 & Cdh13 & Cadherin-13 & 2 & 175.15 & 0.0204 & 89.06 \\
\hline P31725 & S100a9 & Protein S100-A9 & 2 & 127.94 & 0.0142 & 83.63 \\
\hline Q60854 & Serpinb6 & Serpin B6 & 2 & 130.39 & 0.0001 & 77.55 \\
\hline P11276 & Fn1 & Fibronectin & 3 & 163.85 & 0.0018 & 20.87 \\
\hline P09541 & Myl4 & Myosin light chain 4 & 2 & 163.42 & $4.48 \mathrm{E}-06$ & 17.59 \\
\hline P13541 & Myh3 & Myosin-3 & 10 & 604.8 & 0.0047 & 14.13 \\
\hline Q922F4 & Tubb6 & Tubulin beta- 6 chain & 4 & 234.39 & 0.0006 & 9.08 \\
\hline Q3THE2 & Myl12b & Myosin regulatory light chain 12B & 2 & 109.11 & 0.0114 & 9.03 \\
\hline P62270 & Rps18 & 40S ribosomal protein $\mathrm{S} 18$ & 3 & 203.22 & 0.0004 & 8.71 \\
\hline Q8VDD5 & Myh9 & Myosin-9 & 2 & 146.64 & 0.0050 & 8.69 \\
\hline $\mathrm{P} 18760$ & Cfll 1 & Cofilin-1 & 3 & 250.83 & $1.34 \mathrm{E}-05$ & 7.01 \\
\hline P62242 & Rps8 & $40 \mathrm{~S}$ ribosomal protein $\mathrm{S} 8$ & 2 & 144.03 & 0.0218 & 6.60 \\
\hline P26041 & Msn & Moesin & 2 & 110.08 & 0.0004 & 6.30 \\
\hline P09103 & $\mathrm{P} 4 \mathrm{hb}$ & Protein disulfide-isomerase & 3 & 162.63 & 0.0009 & 5.98 \\
\hline P10107 & Anxa1 & Annexin A1 & 3 & 216.16 & $1.47 \mathrm{E}-05$ & 5.90 \\
\hline P51881 & Slc25a5 & ADP/ATP translocase 2 & 2 & 132.1 & 0.0030 & 5.83 \\
\hline Q9WVA4 & Tagln 2 & Transgelin-2 & 3 & 169.11 & 0.0001 & 5.47 \\
\hline P27773 & Pdia3 & Protein disulfide-isomerase A3 & 8 & 465.71 & $6.35 \mathrm{E}-06$ & 5.33 \\
\hline P24369 & Ppib & Peptidyl-prolyl cis-trans isomerase & 2 & 169.3 & 0.0014 & 5.08 \\
\hline P16045 & Lgals1 & Galectin-1 & 3 & 294.54 & 0.0003 & 4.68 \\
\hline Q8CI43 & Myl6b & Myosin light chain 6B & 2 & 151.26 & $3.16 \mathrm{E}-05$ & 4.65 \\
\hline P62281 & Rps11 & 40S ribosomal protein $S 11$ & 2 & 116.64 & 0.0056 & 4.54 \\
\hline P62264 & Rps14 & 40S ribosomal protein S14 & 3 & 221.92 & 0.0014 & 4.43 \\
\hline Q9CZX8 & Rps19 & 40S ribosomal protein $\mathrm{S} 19$ & 3 & 139.44 & 0.0001 & 4.29 \\
\hline P28653 & Bgn & Biglycan & 4 & 288.89 & 0.0048 & 4.17 \\
\hline P13020 & Gsn & Gelsolin & 6 & 433.48 & 0.0001 & 4.15 \\
\hline P60867 & Rps20 & $40 \mathrm{~S}$ ribosomal protein $\mathrm{S} 20$ & 3 & 208.74 & 0.0036 & 4.13 \\
\hline P19324 & Serpinh1 & Serpin H1 & 5 & 283.56 & $2.97 \mathrm{E}-05$ & 4.12 \\
\hline P0C0S6 & $\mathrm{H} 2 \mathrm{afz}$ & Histone H2A.Z & 2 & 98.13 & 0.0013 & 4.09 \\
\hline P80314 & Cct2 & T-complex protein 1 subunit beta & 2 & 142.27 & 0.0070 & 4.05 \\
\hline
\end{tabular}

Supplementary Table S1 lists additional proteins with an increased abundance change below fourfold

conditions to accommodate the binding properties of the specific antibody used to detect biglycan. Optimization studies were carried out to achieve proper immunolabelling of biglycan under reducing versus non-reducing conditions (not shown). In contrast to comparable band patterning in protein gels (Fig. 7a, d, g) and unchanged laminin levels (Fig. 7b, e, h), immuno-decoration of biglycan revealed drastic increases in dystrophin-deficient $m d x$ quadriceps femoris, longissimus dorsi and diaphragm muscle (Fig. 7c, f, i). Interestingly, biglycan expression does not appear to be affected in $m d x$ heart (Fig. 7l). Equal loading of cardiac muscle samples was demonstrated with immunoblotting of lamin isoform B1 (Fig. 7j, k). Figure 8 shows graphically the statistical analysis of the immunoblot analysis of biglycan.

\section{Discussion}

$\mathrm{X}$-linked muscular dystrophy is a multi-system disorder with chronic skeletal muscle degeneration that is accompanied by sterile inflammation, fatty tissue replacement and reactive myofibrosis (Holland et al. 2016), as well as late-onset cardiomyopathy and cognitive impairments in a select number of patients (Guiraud et al. 2015). The pathophysiological complexity of dystrophinopathies therefore warrants detailed large-scale investigations into dystrophin and the molecular pathogenesis triggered by the primary deficiency in this essential membrane cytoskeletal component. However, the large size of the supramolecular assembly of full-length dystrophin and its tightly associated membrane proteins, as well as its relatively low abundance in crude tissue extracts, 

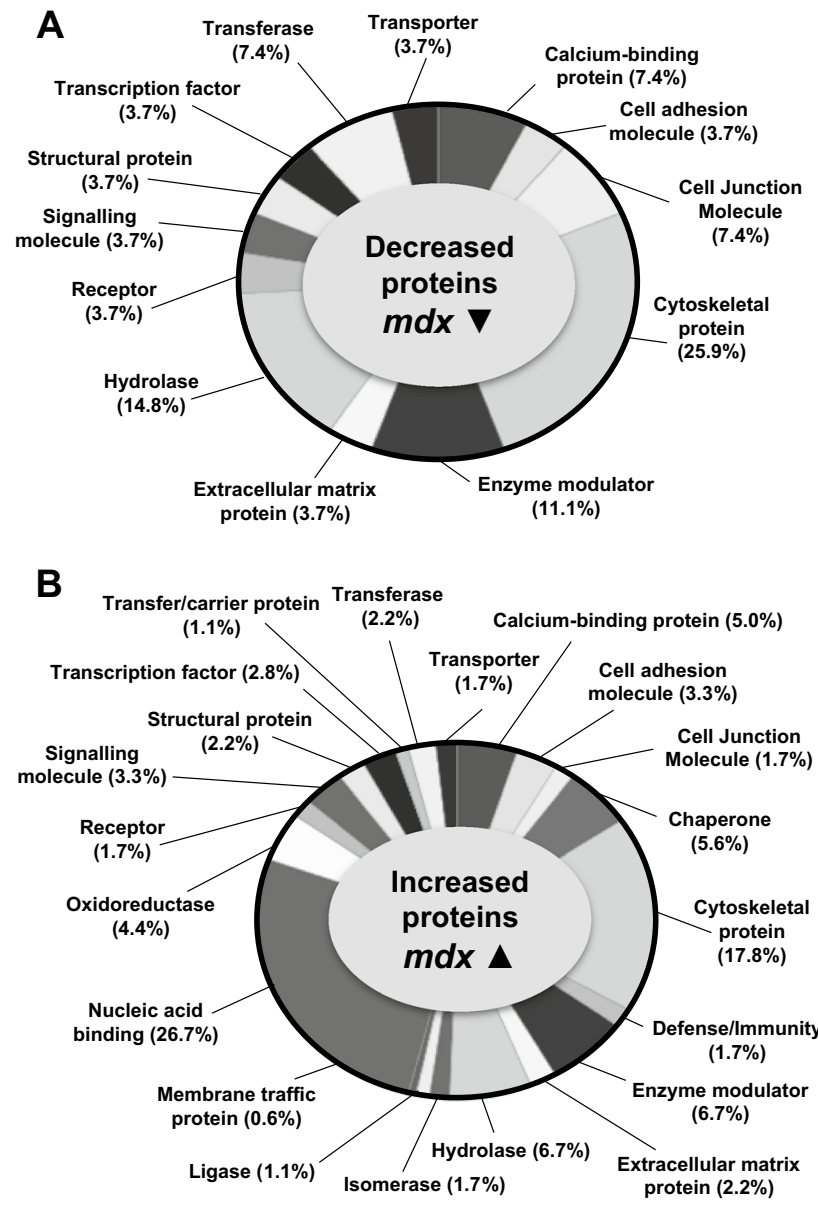

Fig. 5 Summary of altered protein classes in the membrane-enriched fraction from $m d x$ quadriceps femoris muscle. The bioinformatics software programme PANTHER (Mi et al. 2013) was used to summarize the clustering of protein classes based on the mass spectrometric analysis of the membrane-enriched fraction from $m d x$ versus wild type muscle (Tables 3, 4, as well as supplementary Table S1)

make its systematic proteomic characterization technically challenging (Murphy and Ohlendieck 2015). To address this bioanalytical issue, the proteomic analysis described in this report employed a comprehensive approach consisting of both the mass spectrometric identification of novel dystrophin-associated proteins and a comparative analysis of complex protein changes in the membrane-enriched fraction from dystrophic $m d x$ quadriceps muscle. Thus, the main underlying objectives of this investigation were the proteomic establishment of dystrophin-associated proteins and the systematic analysis of major secondary changes in dystrophin-deficient muscle.

The mass spectrometric analysis of the dystrophin complex using interaction proteomics suggests that the cytolinker proteins desmoglein and desmoplakin (Boyer et al. 2010) might interact directly or indirectly with core members of the dystrophin complex. Desmoglein isoform
DSG1 and desmoplakin are sarcolemma-associated proteins and are well-established components of heart desmosomes (Sonnenberg and Liem 2007) with a primary involvement in cardiomyopathy (Brooke et al. 2012). However, both proteins appear to exist at a much lower concentration also in voluntary muscles as compared to the heart. The functional significance of cytolinker proteins is not well characterized in skeletal muscles (Kljuic and Christiano 2003), making it difficult to precisely categorize desmoglein/desmoplakin function. In general, the main contractile, stabilizing and cytoskeletal proteins belonging to the sarcomeric units and its associated subcellular structures can be categorised into (1) the core contractile elements of the actomyosin apparatus, including myosin heavy chains, myosin light chains, actins, troponins and tropomyosins, (2) the supportive skeleton of the sarcomere with its high-molecular-mass components titin, nebulin, myosin binding proteins, $\alpha$-actinin and myomesin, (3) the associated cytoskeletal network consisting of tubulin, desmin and cortical actin, and (4) the membrane cytoskeleton-associated proteins spectrin, talin, dystrophin, ankyrin and vinculin (Holland and Ohlendieck 2013).

Desmoglein and desmoplakin probably fall into an additional category of proteins involved in cytolinking and cellular adhesion, such as those protein complexes present in cardiac desmosomes (Sonnenberg and Liem 2007). Since desmoglein isoform DSG1 levels are greatly reduced in muscular dystrophy, which is a pathobiochemical hallmark of all dystrophin-associated proteins in muscular dystrophy (Ohlendieck et al. 1993), they might represent novel dystrophin-associated proteins of low abundance that are possibly involved in cell-cell adhesion processes in skeletal muscle tissue. Thus, besides the core dystrophin-glycoprotein complex consisting of sarcoglycans, dystroglycans, dystrobrevins, syntrophins, sarcospan, laminin and actin (Ervasti et al. 1990), as confirmed by detailed proteomic studies (Yoon et al. 2012; Turk et al. 2016), dystrophin also links indirectly to the wider extracellular and intracellular matrix (Bowe et al. 2000; Stone et al. 2005; Rezniczek et al. 2007). The loss of dystrophin appears to affect the entire structural linkage between the extracellular collagen/proteoglycan network and the internal cytoskeleton resulting in impaired lateral transmission of contractile force in dystrophic skeletal muscles (Ramaswamy et al. 2011).

Interestingly, the comparative proteomic analysis of $m d x$ skeletal muscles and independent verification by immunoblotting established significantly increased levels of the extracellular matrix proteins fibronectin and biglycan (Bowe et al. 2000; Mercado et al. 2006). This agrees with the idea of severe myofibrosis playing a key role in the molecular pathogenesis of muscular dystrophy (Holland et al. 2016). Among the tested subtypes of skeletal muscle, the biglycan increase was most pronounced in the diaphragm muscle. 


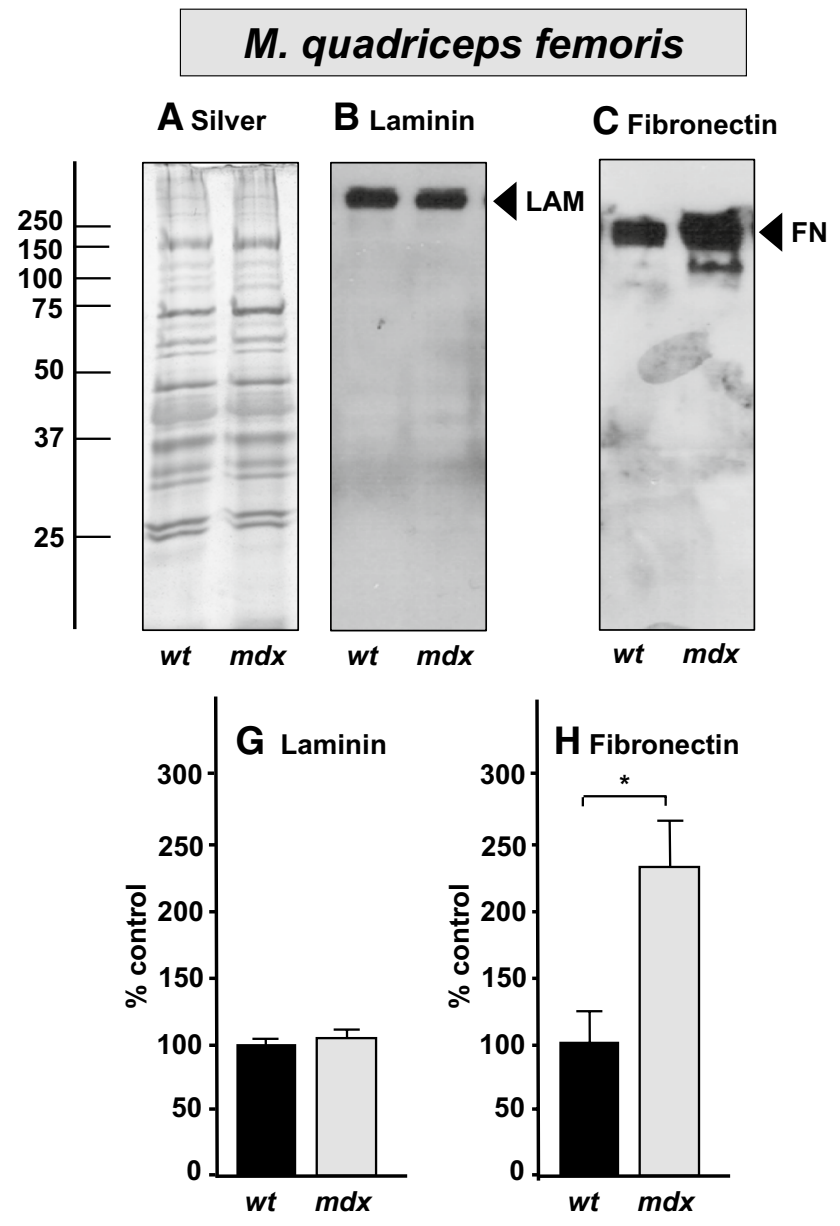

Fig. 6 Immunoblot analysis of fibronectin in dystrophin-deficient skeletal muscle extracts. Shown are silver-stained gels $(A, D)$ and corresponding immunoblots labelled with antibodies to the basal lamina component laminin (LAM; $B, E$ ), and the extracellular matrix protein fibronectin (FN; $C, F)$. Lanes 1 and 2 represent 100-day-old wild type (wt) versus age-matched $m d x$ quadriceps femoris $(A-C)$ and longis-

This result agrees with the previous findings that the diaphragm is preferentially affected in the $m d x$ mouse and the only muscle showing severe fibre wasting and myofibrosis at early stages (Stedman et al. 1991; Steinberger et al. 2015). Since elevated biglycan levels were previously also established as damage markers (Nastase et al. 2012), these proteomic alterations may be useful to establish new biomarker candidates of dystrophinopathy-related myofibrosis (Ohlendieck and Swandulla 2017).

In addition to fibronectin and biglycan, other key extracellular matrix components also showed an increased abundance in dystrophic muscle tissue, including the leucinerich repeat proteins prolargin and asporin, as well as the collagen binding protein serpin H1. Besides dystrophin, a drastic reduction was established for the extracellular protease named kallikrein 1-related peptidase b9, which mediates major endopeptidase activity. It is difficult to interpret

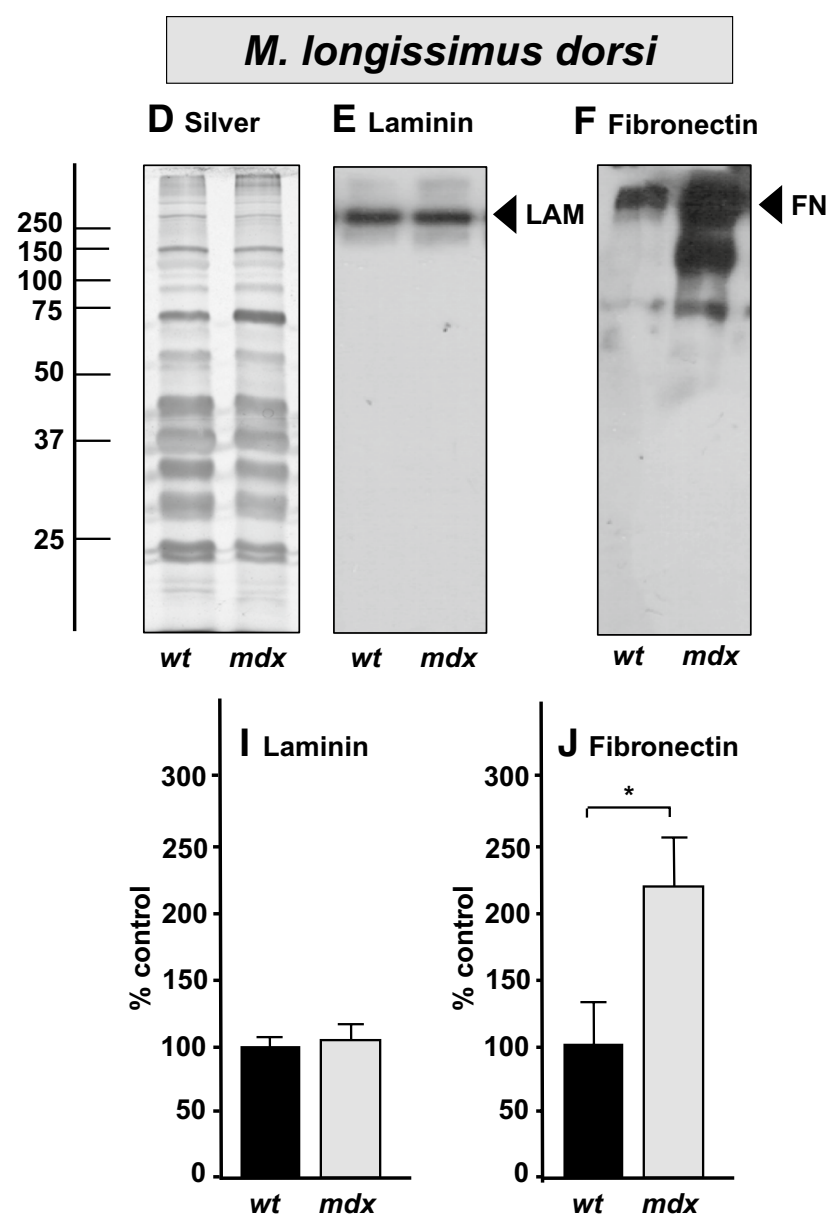

simus dorsi $(D-F)$ muscle, respectively. Molecular mass standards are marked on the left of panels. The comparative blotting between crude extracts from wild type versus $m d x$ mice was statistically evaluated using an unpaired Student's $t$ test (Mean values $\pm \mathrm{SEM} ; \mathrm{n}=4$; $* \mathrm{p}<0.05 ; G-J)$

this pathophysiological change, but the functions of the kallikrein-related peptidases are believed to intersect with the class of matrix metalloproteinases (Yoon et al. 2013). This functional protease axes appears to be affected by pathological dysregulation and might therefore influence the activity patterns of matrix metalloproteinases, which are major control factors in extracellular matrix remodelling. Thus, reduced levels of the kallikrein-related peptidase might play a role in fibrosis.

Besides reactive myofibrosis, changes in a considerable number of protein families may be related to muscle regeneration, remodelling of the contractile apparatus and cytoskeleton, as well as an increased cellular stress response and immune cell infiltration (Shin et al. 2013; Spencer and Tidball 2001). Considerable alterations in the density of nucleic acid binding proteins, hydrolases and many other types of enzymes were observed, suggesting a significant impact of 

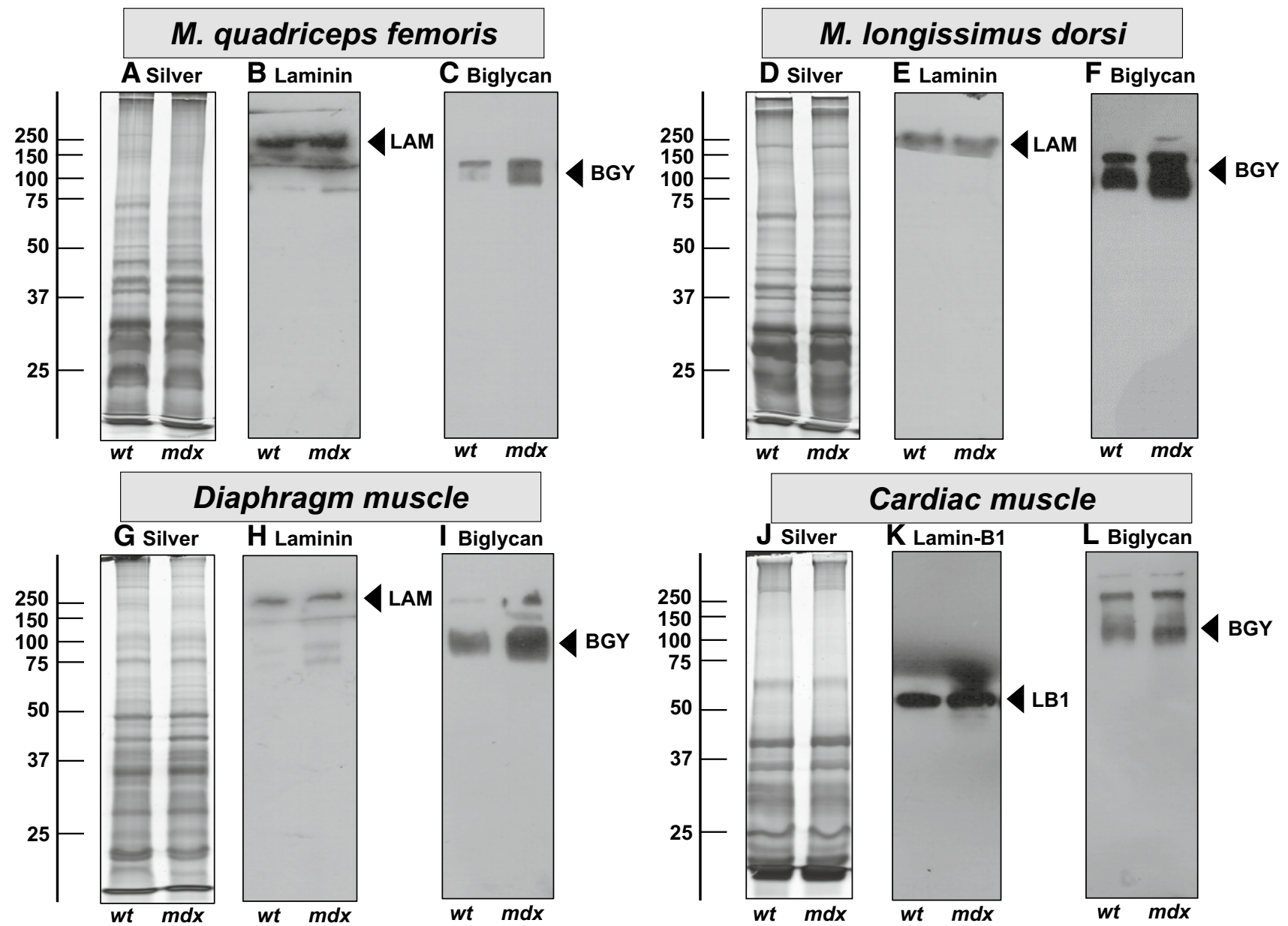

Fig. 7 Immunoblot analysis of biglycan in dystrophin-deficient muscle extracts. Shown are silver-stained gels $(A, D, G, J)$ and corresponding immunoblots labelled with antibodies to the basal lamina component laminin (LAM; $B, E, H$ ), the nuclear protein lamin B1 $(\mathrm{LB} 1 ; K)$ and the extracellular matrix protein biglycan (BGY; $C, F$,

$I, L)$. Lanes 1 and 2 represent 100-day-old wild type (wt) versus age-

dystrophin deficiency on many essential cellular processes (Allen et al. 2016). Decreases and increases were especially observed in the class of cytoskeletal proteins, which agrees with the primary abnormality in a membrane cytoskeletal protein and the compensatory up-regulation of the microtubular protein tubulin and the intermediate filament protein vimentin, as well as moesin, which mediates connections between the plasmalemma and cytoskeletal structures (Lambert et al. 2016). An interesting protein with a reduced concentration is the FABP1 isoform of fatty acid-binding protein. Its concentration change agrees with the idea of altered metabolic rates in muscular dystrophy. Overall, the list of increased proteins suggested extensive changes in the actomyosin apparatus, adhesion receptor networks, the ribosomal complex and the cellular stress response system that might be related to molecular and cellular adaptations in the mdx quadriceps femoris muscle. The occurrence of muscular dystrophy-related cellular transformation would agree with changes in the shape-change sensitive actin-crosslinking protein transgelin that was previously shown to alter its concentration during fibre type shifting in transforming skeletal muscles (Donoghue et al. 2007).

The observed decreases in slow myosin heavy chain (myosin-7), myosin heavy chain MyHC-2b (myosin-4) and slow myosin light chain MLC3, in conjunction with alterations in the levels of tropomyosins Tpm 1 and Tpm3, the M-line components myomesin- 1 , myomesin- 3 and obscurin, the fast myosin-binding protein MyBP-C, the actin-modulating protein gelsolin and the Z-line protein myozenin, suggest complex changes in sarcomeric organization (Lin et al. 2017) and possibly a certain degree of fibre type shifting in muscular dystrophy (Dowling et al. 2016). This would 
Fig. 8 Significant changes of the extracellular matrix protein biglycan in dystrophic $m d x$ skeletal muscles. Shown is the graphical presentation of the statistical evaluation of the immunoblots depicted in Fig. 7. The comparative blotting between crude extracts from 100-day-old wild type ( $w t)$ versus age-matched $m d x$ mice was statistically evaluated using an unpaired Student's $t$ test (Mean values $\pm \mathrm{SEM} ; \mathrm{n}=4 ; * \mathrm{p}<0.05$, $* * p<0.01)$. Shown is the analysis of laminin, lamin B1 and biglycan using crude extracts from quadriceps femoris muscle $(A, B)$, longissimus dorsi muscle $(C, D)$, diaphragm muscle $(E$, $F)$ and the heart $(G, H)$
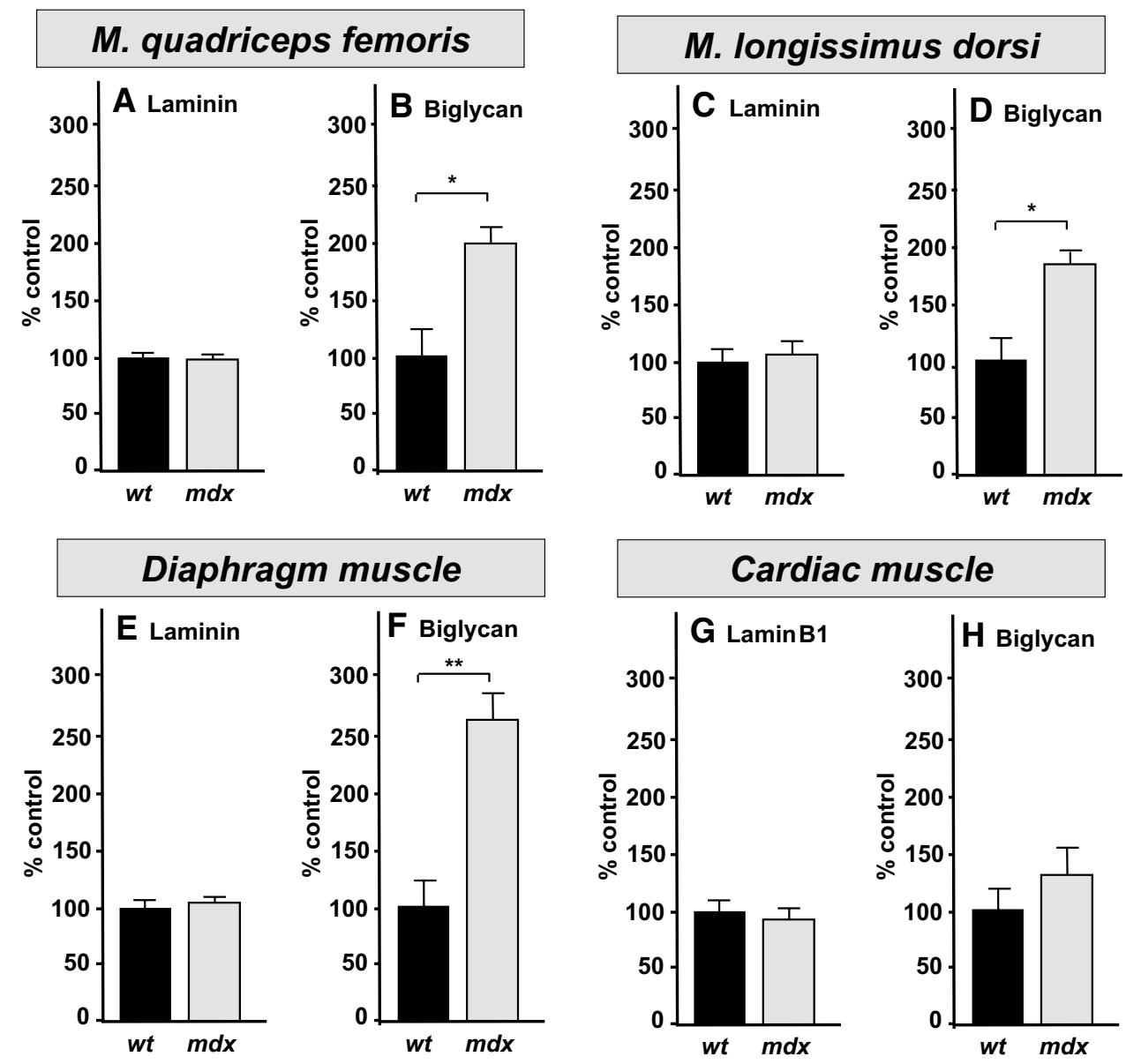

agree with the identified alterations in fibre type-specific isoforms of major $\mathrm{Ca}^{2+}$-regulatory proteins, such as the decreased levels of the fast SERCA1 isoform of the sarcoplasmic reticulum $\mathrm{Ca}^{2+}$-ATPase versus the concomitant increase in the slow isoform of the $\mathrm{Ca}^{2+}$-binding protein calsequestrin of the terminal cisternae region (Culligan et al. 2002). Drastic increases in myosin- 3 and myosin- 8 , which represent embryonic and perinatal isoforms of myosin heavy chains, and the fetal isoform of myosin light chain 4, may be involved in cycles of muscle degeneration and regeneration (Holland et al. 2015). The increased concentration of cellular myosin-9, cofilin-1 and nexilin, which are linked to cytokinesis and cytoskeleton reorganization, may promote cell spreading, cell migration and changes in cell shape during fibre regeneration. Higher levels of the $\mathrm{Ca}^{2+}$-dependent cell adhesion protein cadherin-13 possibly acts as a modifying factor during muscle cell growth, and galectin-1 as a regulator of muscle cell proliferation and fibre differentiation. The proteomic identification of increased obscurin would also agree with enhanced myofibrillogenesis, since this crucial M-line protein plays a central organisational role in myofibrillar assembly during sarcomere changes (Gautel and Djinović-Carugo 2016).
The proteomic analysis of the $m d x$ quadriceps femoris muscle indicated an enhanced cellular stress response, which is in agreement with previous proteomic studies of the severely dystrophic and fibrotic $m d x$ diaphragm (Doran et al. 2006). Drastic increases in the key enzymes protein-disulfide isomerase and peptidyl-prolyl-cis-trans isomerase, as well as a large variety of heat shock proteins including Hsp90-beta, HspA9, HspB1, mitochondrial HspD1, glucose-regulated HspA5, HspB6, T-complex protein 1 and aB-crystallin, demonstrated that molecular chaperones are highly abundant in dystrophin-deficient muscle tissues. These diverse stress proteins are involved in the promotion of accelerated peptide folding to support muscle proteins in resuming their functional fold, the initiation of refolding mechanisms to stabilize compromised protein structures, the aversion of high levels of detrimental protein aggregation and accompanying proteotoxic side effects, as well as the swift removal of irreversibly misfolded protein species (Brinkmeier and Ohlendieck 2014).

In addition to the stress response and cycles of cellular degeneration and regeneration, the immune system also plays a critical role in dystrophinopathies, whereby a key feature of degenerating muscle fibres is immune 
cell infiltration (Villalta et al. 2015). It is not fully understood whether sterile inflammation occurs as a separate pathological process that is independent of muscle fibre degeneration or is triggered by a relatively non-specific and mostly reactive invasion of immune cells in damaged contractile fibres (Rosenberg et al. 2015; Villalta et al. 2014). Biochemical and proteomic studies of the inflammatory pathology of dystrophic muscles have established that progressive muscle wasting is reflected by an altered rate of protein release into the circulatory system and other significant plasma fluctuations (Hathout et al. 2016). Serum analysis using both conventional gel electrophoresis in combination with densitometric scanning (John and Purdom 1989) and label-free LC-MS/MS (Murphy et al. 2017) revealed a significantly increased concentration of the inflammation-inducible plasma marker haptoglobin in muscular dystrophy. Since this acute phase response protein is a reliable marker of inflammation that is usually associated with tissue damage (Wang et al. 2001), dystrophinopathies appear to be closely linked to sterile inflammation. Proteomic findings presented in this report agree with this pathophysiological scenario.

The $\mathrm{Ca}^{2+}-\mathrm{Zn}^{2+}$-binding protein S100-A9, which has a key regulatory role in the immune response and inflammatory processes (Goyette and Geczy 2011), was shown to be drastically increased in dystrophic muscle. The S100a9 gene is regulated by various inflammatory mediators, which alter its expression level within a particular inflammatory milieu. The S100A9 protein is constitutively expressed in neutrophils and can induce neutrophil chemotaxis. Elevated levels of annexin isoform A1 that exhibits anti-inflammatory activity suggest that the innate immune response plays an important part in the molecular pathogenesis of X-linked muscular dystrophy. Various members of the annexin family have previously been identified to exhibit changed expression levels in muscular dystrophy (Holland et al. 2015). The apparent compensatory up-regulation of annexin 1 is an interesting finding, since this annexin isoform acts as a critical regulator of the overall inflammatory process. Annexin 1 was shown to counteract inflammatory events and thereby promotes the restoration of cellular homeostasis (Sugimoto et al. 2016), which might also occur in dystrophin-deficient muscle tissues.

Importantly, the concomitant decrease in the desmoglein/desmoplakin-complex and increase in the biglycan/ fibronectin-network illustrates the complexity of pathobiochemical changes and adaptations in dystrophin-deficient skeletal muscle tissues (Bowe et al. 2000; Amenta et al. 2011). It is remarkable that the proteomic screening procedure described in this report resulted in a successful identification of these new biomarker candidates of muscle damage, since a large number of technical challenges are especially associated with the biochemical and proteomic analysis of muscle tissues. Skeletal muscles are (1) heterogeneous in their cellular composition in relation to different subtypes of contractile fibres, innervating neurons, glia cells, satellite cells and capillaries, (2) highly plastic in their adaptive potential, (3) and surrounded by several layers of connective tissue, which complicates extraction procedures. A serious biochemical problem for efficient protein separation is the large number of high-molecularmass proteins, such as titin, nebulin, obscurin, dysferlin, dystrophin and the ryanodine receptor. Since approximately half of the muscle protein species belong to the contractile apparatus, the potential cross-contamination with myosins, actins, tropomyosins and troponins presents also an investigative difficulty. Thus, pathoproteomic surveys of tissue specimens from muscular dystrophy are not straightforward bioanalytical endeavours.

Although a considerable number of proteomic studies have identified many dystrophinopathy-related secondary alterations in proteins involved in metabolism, signalling events and structural integrity, most large-scale comparative studies have failed to detect dystrophin (Holland et al. 2013). This serious analytical drawback was overcome in this study by using sophisticated subcellular fractionation procedures. In this proteomic study, the drastic reduction in dystrophin could be directly compared with secondary abnormalities in a variety of enzymes, structural proteins and signalling components.

\section{Conclusions}

Interaction proteomics using an analytical co-purification approach identified the cytolinkers desmoglein and desmoplakin as potentially new dystrophin-associated proteins. In analogy to the reduction of all core dystrophin-associated proteins in muscular dystrophy, immunoblotting established significantly lower desmoglein isoform DSG1 levels in dystrophin-deficient muscle tissue. The comparative proteomic profiling of a muscle membrane-enriched fraction from the $m d x$ mouse model of Duchenne muscular dystrophy could furthermore establish increased levels of fibronectin and biglycan of the extracellular matrix. Since the proteoglycan biglycan exists in a close relationship to dystrophin, this finding agrees with a central role of an altered matrisome and reactive myofibrosis in dystrophinopathy.

Acknowledgements Research was supported by project grants from Muscular Dystrophy Ireland and the Irish Health Research Board (HRB/MRCG-2016-20) and a Hume scholarship from Maynooth University. The Q-Exactive quantitative mass spectrometer was funded under the Research Infrastructure Call 2012 by Science Foundation Ireland (SFI-12/RI/2346/3). The authors would like to thank Ms Caroline Batchelor for expert technical support with mass spectrometry. 


\section{References}

Allen DG, Whitehead NP, Froehner SC (2016) Absence of dystrophin disrupts skeletal muscle signaling: roles of $\mathrm{Ca}^{2+}$, reactive oxygen species, and nitric oxide in the development of muscular dystrophy. Physiol Rev 96:253-305

Amenta AR, Yilmaz A, Bogdanovich S, McKechnie BA, Abedi M, Khurana TS, Fallon JR (2011) Biglycan recruits utrophin to the sarcolemma and counters dystrophic pathology in mdx mice. Proc Natl Acad Sci USA 108:762-767

Bowe MA, Mendis DB, Fallon JR (2000) The small leucine-rich repeat proteoglycan biglycan binds to alpha-dystroglycan and is upregulated in dystrophic muscle. J Cell Biol 148:801-810

Boyer JG, Bernstein MA, Boudreau-Larivière C (2010) Plakins in striated muscle. Muscle Nerve 41:299-308

Brinkmeier H, Ohlendieck K (2014) Chaperoning heat shock proteins: proteomic analysis and relevance for normal and dystrophin-deficient muscle. Proteomics Clin Appl 8:875-895

Brooke MA, Nitoiu D, Kelsell DP (2012) Cell-cell connectivity: desmosomes and disease. J Pathol 226:158-171

Campbell KP, Kahl SD (1989) Association of dystrophin and an integral membrane glycoprotein. Nature 338:259-262

Carberry S, Brinkmeier H, Zhang Y, Winkler CK, Ohlendieck K (2013) Comparative proteomic profiling of soleus, extensor digitorum longus, flexor digitorum brevis and interosseus muscles from the mdx mouse model of Duchenne muscular dystrophy. Int J Mol Med 32:544-556

Constantin B (2014) Dystrophin complex functions as a scaffold for signalling proteins. Biochim Biophys Acta 1838:635-642

Culligan K, Banville N, Dowling P, Ohlendieck K (2002) Drastic reduction of calsequestrin-like proteins and impaired calcium binding in dystrophic mdx muscle. J Appl Physiol 92:435-445

Di Luca A, Henry M, Meleady P, O'Connor R (2015) Label-free LC-MS analysis of HER2+ breast cancer cell line response to HER2 inhibitor treatment. Daru 23:40

Donoghue P, Doran P, Wynne K, Pedersen K, Dunn MJ, Ohlendieck K (2007) Proteomic profiling of chronic low-frequency stimulated fast muscle. Proteomics 7:3417-3430

Doran P, Martin G, Dowling P, Jockusch H, Ohlendieck K (2006) Proteome analysis of the dystrophin-deficient MDX diaphragm reveals a drastic increase in the heat shock protein cvHSP. Proteomics 6:4610-4621

Dowling P, Palmerini V, Henry M, Meleady P, Lynch V, Ballot J, Gullo G, Crown J, Moriarty M, Clynes M (2014) Transferrinbound proteins as potential biomarkers for advanced breast cancer patients. BBA Clin 2:24-30

Dowling P, Murphy S, Ohlendieck K (2016) Proteomic profiling of muscle fibre type shifting in neuromuscular diseases. Expert Rev Proteom 13:783-799

Ervasti JM, Ohlendieck K, Kahl SD, Gaver MG, Campbell KP (1990) Deficiency of a glycoprotein component of the dystrophin complex in dystrophic muscle. Nature 345:315-319

Ervasti JM, Kahl SD, Campbell KP (1991) Purification of dystrophin from skeletal muscle. J Biol Chem 266:9161-9165

Fröhlich T, Kemter E, Flenkenthaler F, Klymiuk N, Otte KA, Blutke A, Krause S, Walter MC, Wanke R, Wolf E, Arnold GJ (2016) Progressive muscle proteome changes in a clinically relevant pig model of Duchenne muscular dystrophy. Sci Rep 6:33362

Fuller HR, Graham LC, Llavero Hurtado M, Wishart TM (2016) Understanding the molecular consequences of inherited muscular dystrophies: advancements through proteomic experimentation. Expert Rev Proteom 13:659-671

Gautel M, Djinović-Carugo K (2016) The sarcomeric cytoskeleton: from molecules to motion. J Exp Biol 219:135-145
Goyette J, Geczy CL (2011) Inflammation-associated S100 proteins: new mechanisms that regulate function. Amino Acids 41:821-842

Guevel L, Lavoie JR, Perez-Iratxeta C, Rouger K, Dubreil L, Feron M, Talon S, Brand M, Megeney LA (2011) Quantitative proteomic analysis of dystrophic dog muscle. J Proteome Res 10:2465-2478

Guiraud S, Aartsma-Rus A, Vieira NM, Davies KE, van Ommen GJ, Kunkel LM (2015) The pathogenesis and therapy of muscular dystrophies. Annu Rev Genom Hum Genet 16:281-308

Hathout Y, Seol H, Han MH, Zhang A, Brown KJ, Hoffman EP (2016) Clinical utility of serum biomarkers in Duchenne muscular dystrophy. Clin Proteom 13:9

Holland A, Ohlendieck K (2013) Proteomic profiling of the contractile apparatus from skeletal muscle. Expert Rev Proteom 10:239-257

Holland A, Carberry S, Ohlendieck K (2013) Proteomics of the dystrophin-glycoprotein complex and dystrophinopathy. Curr Protein Pept Sci 14:680-697

Holland A, Henry M, Meleady P, Winkler CK, Krautwald M, Brinkmeier H, Ohlendieck K (2015) Comparative label-free mass spectrometric analysis of mildly versus severely affected mdx mouse skeletal muscles identifies annexin, lamin, and vimentin as universal dystrophic markers. Molecules 20:11317-11344

Holland A, Murphy S, Dowling P, Ohlendieck K (2016) Pathoproteomic profiling of the skeletal muscle matrisome in dystrophinopathy associated myofibrosis. Proteomics 16:345-366

John HA, Purdom IF (1989) Elevated plasma levels of haptoglobin in Duchenne muscular dystrophy: electrophoretic variants in patients with a severe form of the disease. Electrophoresis 10:489-493

Kljuic A, Christiano AM (2003) A novel mouse desmosomal cadherin family member, desmoglein 1 gamma. Exp Dermatol 12:20-29

Lambert M, Richard E, Duban-Deweer S, Krzewinski F, Deracinois B, Dupont E, Bastide B, Cieniewski-Bernard C (2016) O-GlcNAcylation is a key modulator of skeletal muscle sarcomeric morphometry associated to modulation of protein-protein interactions. Biochim Biophys Acta 1860:2017-2030

Lardenois A, Jagot S, Lagarrigue M, Guével B, Ledevin M, Larcher T, Dubreil L, Pineau C, Rouger K, Guével L (2016) Quantitative proteome profiling of dystrophic dog skeletal muscle reveals a stabilized muscular architecture and protection against oxidative stress after systemic delivery of MuStem cells. Proteomics 16:2028-2042

Le Rumeur E, Winder SJ, Hubert JF (2010) Dystrophin: more than just the sum of its parts. Biochim Biophys Acta 1804:1713-1722

Lewis C, Ohlendieck K (2010) Mass spectrometric identification of dystrophin isoform Dp427 by on-membrane digestion of sarcolemma from skeletal muscle. Anal Biochem 404:197-203

Lin BL, Song T, Sadayappan S (2017) Myofilaments: movers and rulers of the sarcomere. Compr Physiol 7:675-692

Liu Y, Bouhenni RA, Dufresnem CP, Semba RD, Edward DP (2016) Differential expression of vitreous proteins in young and mature New Zealand white rabbits. PLoS One 11:e0153560

Luque-Garcia JL, Neubert TA (2009) On-membrane tryptic digestion of proteins for mass spectrometry analysis. Methods Mol Biol 536:331-341

Mercado ML, Amenta AR, Hagiwara H, Rafii MS, Lechner BE, Owens RT, McQuillan DJ, Froehner SC, Fallon JR (2006) Biglycan regulates the expression and sarcolemmal localization of dystrobrevin, syntrophin, and nNOS. FASEB J 20:1724-1726

Mi H, Muruganujan A, Thomas PD (2013) PANTHER in 2013: modeling the evolution of gene function, and other gene attributes in the context of phylogenetic trees. Nucleic Acids Res 41:D377-D386

Muntoni F, Torelli S, Ferlini A (2003) Dystrophin and mutations: one gene, several proteins, multiple phenotypes. Lancet Neurol 2:731-740 
Murphy S, Ohlendieck K (2015) The biochemical and mass spectrometric profiling of the dystrophin complexome from skeletal muscle. Comput Struct Biotechnol J 14:20-27

Murphy S, Henry M, Meleady P, Zweyer M, Mundegar RR, Swandulla D, Ohlendieck K (2015) Simultaneous pathoproteomic evaluation of the dystrophin-glycoprotein complex and secondary changes in the mdx-4cv mouse model of duchenne muscular dystrophy. Biology (Basel) 4:397-423

Murphy S, Dowling P, Zweyer M, Mundegar RR, Henry M, Meleady P, Swandulla D, Ohlendieck K (2016) Proteomic analysis of dystrophin deficiency and associated changes in the aged $\mathrm{mdx}-4 \mathrm{cv}$ heart model of dystrophinopathy-related cardiomyopathy. J Proteom 145:24-36

Murphy S, Dowling P, Zweyer M, Henry M, Meleady P, Mundegar RR, Swandulla D, Ohlendieck K (2017) Proteomic profiling of mdx-4cv serum reveals highly elevated levels of the inflammation-induced plasma marker haptoglobin in muscular dystrophy. Int J Mol Med 39:1357-1370

Nastase MV, Young MF, Schaefer L (2012) Biglycan: a multivalent proteoglycan providing structure and signals. J Histochem Cytochem 60:963-975

O'Connell K, Ohlendieck K (2009) Proteomic DIGE analysis of the mitochondria-enriched fraction from aged rat skeletal muscle. Proteomics 9:5509-5524

Ohlendieck K (1996) Towards an understanding of the dystrophin-glycoprotein complex: linkage between the extracellular matrix and the membrane cytoskeleton in muscle fibers. Eur J Cell Biol 69:1-10

Ohlendieck K, Swandulla D (2017) Molecular pathogenesis of Duchenne muscular dystrophy-related fibrosis. Pathologe 38:21-29

Ohlendieck K, Ervasti JM, Snook JB, Campbell KP (1991) Dystrophinglycoprotein complex is highly enriched in isolated skeletal muscle sarcolemma. J Cell Biol 112:135-148

Ohlendieck K, Matsumura K, Ionasescu VV, Towbin JA, Bosch EP, Weinstein SL, Sernett SW, Campbell KP (1993) Duchenne muscular dystrophy: deficiency of dystrophin-associated proteins in the sarcolemma. Neurology 43:795-800

Ramaswamy KS, Palmer ML, van der Meulen JH, Renoux A, Kostrominova TY, Michele DE, Faulkner JA (2011) Lateral transmission of force is impaired in skeletal muscles of dystrophic mice and very old rats. J Physiol 589:1195-1208

Rayavarapu S, Coley W, Cakir E, Jahnke V, Takeda S, Aoki Y, Grodish-Dressman H, Jaiswal JK, Hoffman EP, Brown KJ, Hathout Y, Nagaraju K (2013) Identification of disease specific pathways using in vivo SILAC proteomics in dystrophin deficient mdx mouse. Mol Cell Proteom 12:1061-1073

Rezniczek GA, Konieczny P, Nikolic B, Reipert S, Schneller D, Abrahamsberg C, Davies KE, Winder SJ, Wiche G (2007) Plectin $1 \mathrm{f}$ scaffolding at the sarcolemma of dystrophic (mdx) muscle fibers through multiple interactions with beta-dystroglycan. J Cell Biol 176:965-977

Roberts TC, Johansson HJ, McClorey G, Godfrey C, Blomberg KE, Coursindel T, Gait MJ, Smith CI, Lehtiö J, El Andaloussi S, Wood MJ (2015) Multi-level omics analysis in a murine model of dystrophin loss and therapeutic restoration. Hum Mol Genet 24:6756-6768

Rosenberg AS, Puig M, Nagaraju K, Hoffman EP, Villalta SA, Rao VA, Wakefield LM, Woodcock J (2015) Immune-mediated pathology in Duchenne muscular dystrophy. Sci Transl Med 7:299rv4

Shevchenko A, Tomas H, Havlis J, Olsen JV, Mann M (2006) In-gel digestion for mass spectrometric characterization of proteins and proteomes. Nat Protoc 1:2856-2860
Shin J, Tajrishi MM, Ogura Y, Kumar A (2013) Wasting mechanisms in muscular dystrophy. Int J Biochem Cell Biol 45:2266-2279

Sonnenberg A, Liem RK (2007) Plakins in development and disease. Exp Cell Res 313:2189-2203

Spencer MJ, Tidball JG (2001) Do immune cells promote the pathology of dystrophin-deficient myopathies? Neuromuscul Disord 11:556-564

Staunton L, Ohlendieck K (2012) Mass spectrometric characterization of the sarcoplasmic reticulum from rabbit skeletal muscle by onmembrane digestion. Protein Pept Lett 19:252-263

Stedman HH, Sweeney HL, Shrager JB, Maguire HC, Panettieri RA, Petrof B, Narusawa M, Leferovich JM, Sladky JT, Kelly AM (1991) The mdx mouse diaphragm reproduces the degenerative changes of Duchenne muscular dystrophy. Nature 352:536-539

Steinberger M, Föller M, Vogelgesang S, Krautwald M, Landsberger M, Winkler CK, Kasch J, Füchtbauer EM, Kuhl D, Voelkl J, Lang F, Brinkmeier H (2015) Lack of the serum- and glucocorticoidinducible kinase SGK1 improves muscle force characteristics and attenuates fibrosis in dystrophic mdx mouse muscle. Pflügers Arch 467:1965-1974

Stone MR, O’Neill A, Catino D, Bloch RJ (2005) Specific interaction of the actin-binding domain of dystrophin with intermediate filaments containing keratin 19. Mol Biol Cell 16:4280-4293

Sugimoto MA, Vago JP, Teixeira MM, Sousa LP (2016) Annexin A1 and the resolution of inflammation: modulation of neutrophil recruitment, apoptosis, and clearance. J Immunol Res 2016:8239258

Turk R, Hsiao JJ, Smits MM, Ng BH, Pospisil TC, Jones KS, Campbell KP, Wright ME (2016) Molecular signatures of membrane protein complexes underlying muscular dystrophy. Mol Cell Proteom 15:2169-2185

Ursitti JA, Lee PC, Resneck WG, McNally MM, Bowman AL, O'Neill A, Stone MR, Bloch RJ (2004) Cloning and characterization of cytokeratins 8 and 19 in adult rat striated muscle. Interaction with the dystrophin glycoprotein complex. J Biol Chem 279:41830-41838

Villalta SA, Rosenthal W, Martinez L, Kaur A, Sparwasser T, Tidball JG, Margeta M, Spencer MJ, Bluestone JA (2014) Regulatory T cells suppress muscle inflammation and injury in muscular dystrophy. Sci Transl Med 6:258ra142

Villalta SA, Rosenberg AS, Bluestone JA (2015) The immune system in Duchenne muscular dystrophy: friend or foe. Rare Dis 3:e1010966

Wang Y, Kinzie E, Berger FG, Lim SK, Baumann H (2001) Haptoglobin, an inflammation-inducible plasma protein. Redox Rep 6:379-385

Yoon JH, Johnson E, Xu R, Martin LT, Martin PT, Montanaro F (2012) Comparative proteomic profiling of dystroglycan-associated proteins in wild type, $\mathrm{mdx}$, and Galgt 2 transgenic mouse skeletal muscle. J Proteome Res 11:4413-4424

Yoon H, Blaber SI, Li W, Scarisbrick IA, Blaber M (2013) Activation profiles of human kallikrein-related peptidases by matrix metalloproteinases. Biol Chem 394:137-147

Zschüntzsch J, Zhang Y, Klinker F, Makosch G, Klinge L, Malzahn D, Brinkmeier H, Liebetanz D, Schmidt J (2016) Treatment with human immunoglobulin $\mathrm{G}$ improves the early disease course in a mouse model of Duchenne muscular dystrophy. J Neurochem $136: 351-362$ 